\title{
The impacts of expansion and degradation on Australian cropping yields-An integrated historical perspective
}

\author{
Graham M. Turner ${ }^{\text {a,b, }}$, Michael Dunlop ${ }^{\text {a }}$, Seona Candy c \\ a CSIRO Ecosystem Sciences, Canberra, ACT, Australia \\ b Melbourne Sustainable Society Institute, University of Melbourne, Parkville, Vic, Australia \\ c Victorian Eco-Innovation Lab, University of Melbourne, Parkville, Vic, Australia
}

\begin{abstract}
A b s t r a c t
Using a 'stocks and flows' model of Australian cropping we show that the expansion of aggregate cropping area has effectively masked landscape degradation impacts associated with continual production activity on "ageing" land. We estimate yield loss from combined land degradation to have increased to $9 \%$, though the aggregate impact has effectively been masked by the introduction of new land. The model tracks the vintage of land since its first introduction to the agricultural system and calculates landscape degradation for four modes (dry-land salinity, irrigation salinity, acidification, and soil structure decline) according to historical production and ameliorating activities on each vintage. The model is calibrated with over 140 years of varied historical data from the 1850s. Modelled farm-gate production volumes also incorporate techmological factors, such as genetic and other yield increases. Despite the introduction of many technologicaladvances in the cropping industry through the middle of the 20th century, production yields of Australian cereal grain remained relatively unchanged for decades. This can be explained by the rapid ageing and degradation of the cropping land due to a period of halted expansion. This perspective has important implications forfuture scenarios of the Australian cropping industry, which are unlikely to maintain land expansion at the long-term average of about $2 \%$ pa. Without major change, land degradation in our model results in yield loss of early 30\% by 2060.
\end{abstract}

\section{Introduction}

Agriculture has contributed enormously to the economic growth of Australia in the last 200 years, and continues to be a major source of food and fibre for international and domestic markets, as well as export income (Pollard, 2000). However, one of the most notable features of this sector over this history has been the considerable increase in the amount of land and water resources used.

While these resources are ostensibly renewable, in practice the past use of land, water and ecosystem resources has frequently not been in a renewable manner; Australia State of the Environment (ASEC, 2002). The National Land and Water Resource Audit ${ }^{1}$ (NLWRA, 2002), including the Australian Natural Resources Atlas and the series of Assessment Reports, reveals evidence of wide-scale erosion of Australia's natural resource capital. Increasing dryland salinity and declining river health are two well-recognised examples that illustrate the widespread and complex nature of the issues. While public attention to dryland salinity has waned over the past decade (due largely to decreased rainfall helping to lower saline water tables), the impact of several modes of land degradation on crop yield remains significant.

In some other major crop producing regions, yields appear to have reached a plateau (Grassini et al., 2013). Yet to feed the potential future global population, future yield growth needed to 2030 is estimated to be similar to past global rates (of about $40-60 \mathrm{~kg} / \mathrm{ha} / \mathrm{a}$ for key cereal crops) (Gregory and George, 2011). Evidently there is a pressing need for research into how to close the 'yield gap' (between potential and average actual yield) (van Ittersum and Cassman, 2013), though this is likely to be challenging due in part to questions of regional differences and scale issues (van Ittersum et al., 2013).

Our modelling research sought to explore future scenarios of the Australian agricultural industry, with a focus on crop production and sustainability (Dunlop and Turner, 2003; Dunlop et al., 2002). This was grounded in an integrated understanding of the history of Australian agriculture and the grains industry, which does more than simply set the scene for possible future scenarios, as we present in this paper. Historical developments impose constraints on possible future actions, through a sort of inertia associated with stocks of land. Additionally, important lessons can be drawn from historical developments, especially when considered in an integrated framework that captures the interactions between factors such as land intensification, landscape degradation, and water use. 


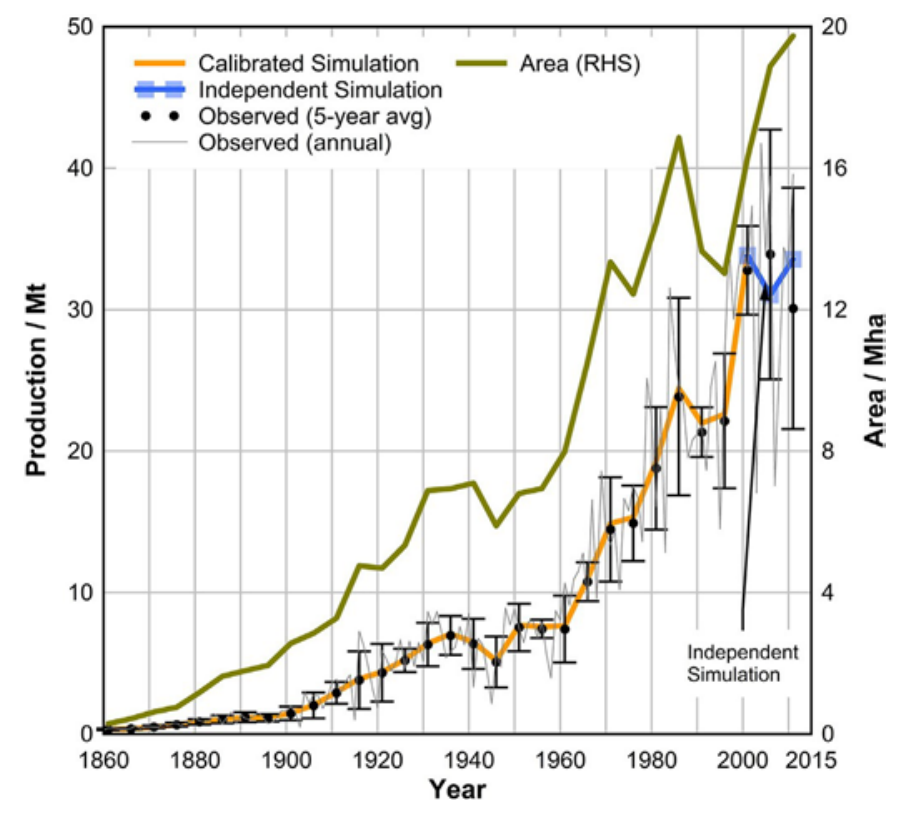

Fig. 1. Comparison of simulated cereal grain production with observed data (thin line shows annual data; solid circles with standard deviation error bars show 5-year averages). Simulated production is calibrated to the observed data up to 2001. Beyond this, independently simulated 5-year production for 2006 and 2011 (square symbols with blue line) is close to observed production. Area of cereal grain cropping is also shown (RHS). (For interpretation of the references to colour in this figure legend, the reader is referred to the web version of this article.)

In this paper, we first review the history of Australian agriculture and the grains industry from a nationally aggregated view of key factors and indicators, pulling these together into an integrated picture that reveals the long-term drivers of change. This suggests the key factors and relationships required in our model, which is briefly described. Particular emphasis is given to explaining the part played by the age structure of crop and pasture land, and the associated concept of landscape condition or degradation. As in other sectors of the economy that are based on stocks of infrastructure and resources, the age structure concept and its implications are key elements for understanding the historical progress of the grains industry, and for designing future scenarios. We document how these key elements were calibrated, and show how historical crop (cereal) yield has been impacted. Our analysis focuses on cereals as the dominant Australian crop, though we also present data for broader intensive agriculture (all crops and sown pasture) due to the integrated nature of our system modelling and analysis. Some illustrative implications of constraints in land expansion on future yield dynamics are explored using the model, and we finish by discussing possible modelling and research issues/questions.

\section{Integrated long-term overview of progress in the Australian grains industry}

Many technological, process and environmental developments have occurred in the Australian grains industry over the past 150 years. We consider the various factors in an integrated manner so that we may identify the slow moving changes that are likely to impact on the future of the grains industry. In addition to the historical data assembled in our model, this broad overview draws on a number of historical reviews of the agricultural sector (Camm and McQuilton, 1987; Pollard, 2000; Shaw and Davidson, 1995; Tribe and Peel, 1988).

An overview of the impact of technology (and other factors) on the productivity of the grains industry is presented in the national average cereal grain yield (t/ha) (NLWRA, 2001) (Fig. 2a and the bar chart depicting the extent of major events and developments relevant to the grains industry over the same time period (Fig. 2b). The graph of cereal grain yield shows annual data as well as moving averages calculated for 5 and 15 year periods, with the longer averaging recommended for Australia's highly variable production (van Ittersum et al., 2013). By smoothing out the short-term fluctuations, the moving averages clearly show the leaps and plateaus of yield over the past century (in contrast with the impression of a continual linear increase since 1900 as presented in the NLWRA (2001)).

Broadly, the trends shown in Fig. 2a indicate four historical periods of different yield development.

- From 1850 to about 1900 there was a strong decrease in the yield. This is typically attributed to nutrient depletion of soils (Burch et al., 1987; Hamblin and Kyneur, 1993), although the situation was unlikely to be this simple, as discussed below.

- After the turn of the century there is rapid increase in the yield over one or two decades. By 1930 the (long-term) yield increase from that at 1900 was approximately $70 \%$.

- However, this trend for rapid increase saturates so that for the next four decades there was relatively little long-term change in average yield, increasing by about $10 \%$.

- In stark contrast, a powerfulyield increase of roughly $70 \%$ occurred over the period from 1970 until the end of the 20th century. Earlier research (Burch et al., 1987; Hamblin and Kyneur, 1993) depicts this period as a second saturating trend.

Previous reviews ((Burch et al., 1987; Hamblin and Kyneur, 1993), based on (Donald and Williams, 1982)) of the trends in wheat yields from the late 1800 s to the late 1900s have also identified distinct phases, namely a decreasing period to 1900 followed by two saturating trends. These reviews also indicate the introduction of a number of technological factors or crop management techniques that have impacted on crop productivity. Despite raising concerns that land degradation underlies at least some of the limited growth in yield, these reviews have not explicitly considered the influence of the introduction of new land, or more specifically, the age of the extant cropping land.

Comparison of the bar chart of Fig. 2 with the yield curve highlights the importance of various drivers (including but not limited to technology) on yield improvement. An important but evidently short-term (1-10 years) effect is the impact that strong droughts (an 'environmental climate' factor in Fig 1) have on the yearly yield. In comparison, droughts that are classified as medium or low (not shown on the bar chart) (see NLWRA, 2001) do not have a substantial affect. This difference points to the importance of geographic variation: the impact of less substantial droughts is ameliorated by higher yields in areas that are not drought affected. Other factors operate over longer periods, as the following review chronicles.

\section{1. $1850-1900$}

Prior to the beginning of the 20th century there was a general expansion of agricultural area-from 1850 to 1900 the area increased by a factor of more than 25 times for cereal grain. This was accompanied by a considerable decline in the overall productivity as shown by the average yield from 1850 to 1900 . The average yield decreased by roughly $70 \%$ over this time.

The yield reduction is commonly attributed to soil nutrient depletion resulting from sustained poor farming practices (e.g., Donald and Williams, 1982; Hamblin and Kyneur, 1993). In particular, the practice of incorporating fodder crop rotations was not employed even though this was recognised (in the UK and Europe) as an important way to provide nutrients through manure application and nitrogen fixation (Henzell, 2007). Consequently, continuous cropping led to nutrient depletion. Other factors may have played a role. For instance, expansion into areas of less fertile soils and the use of grain varieties not suitable for the different soil and climatic conditions have also been implicated 
(Camm and McQuilton, 1987; Shaw and Davidson, 1995; Tribe and Peel, 1988).

\section{2. $1900-1930$}

After the turn of the century (and the severe drought ending in 1903), average yield increased markedly, virtually doubling within two decades. Like the changes before 1900, it is tempting to attribute the improvements to a primary factor, in this case the introduction of the 'Federation' wheat strain.

However, in the early decades of the 20th century other technological developments also played a role in expanding cropping area through the introduction and growth of bulk transport systems connecting production with overseas markets. (Later in the century the impact of transport technology more likely improved the quality of the cropping product compared with expanding the quantity.) The area farmed doubled in the space of a decade as a result of several drivers including "closer settlement" domestic policy (and soldier settlement), introduced mechanisation (such as the scrub roller and stump jump plough), and an expanding rail network. This new land may have acted in combination with the new varieties introduced to produce the substantial yield increase in the early part of this period.

In addition, tractors were introduced and quite apart from any direct improvements (or possible damages on soil structure) these may have made in farming practice, an indirect positive impact may have occurred through the release of grain that would otherwise have been consumed by farm workhorses.

It is also noteworthy that in the last decade of this period further technology was introduced in the form of superphosphate and subterranean clover. The "sub and super" aspect has been heralded as a key to the substantial gains made by the Australian grains industry (Tribe and Peel, 1988).

Despite these technological improvements in the 20s, it is interest ing that the average yield increase was marginal at best. This seems to suggest that any improvements were being countered by another factor, as the review of two periods suggests.

\section{3. $1930-1950$}

In these decades, the output of cropping was effectively stagnated. In terms of demand, this was a period of relatively high instability. There were no substantial sustained land increases, which correlates with the combination of reduced international demand for grains and land used for grazing ('livestock competition' for Yand), where for example demand for wool as a result of the Korean War pushed up the number of sheep. Consequently, the area cropped did not increase (fluctuating around an average of about $7 \mathrm{Mha}$ ). Nor did the yield increase in any substantial way.

This situation occurred despite continuous technological improvements, including the introduction of new grain varieties (by 1930 the
Federation strain was all but replaced), and increasing inputs in the form of superphosphate. Possibly a shorter-term down- and upswing in the yield (e.g., 5-year average) is associated with Second World War restrictions and subsequent access to fertiliser.

\section{4. $1950-1970$}

The two decades after the Second World War, saw relatively minor yield recovery even though nutrients, pesticides and herbicides were introduced with the aid of better delivery systems such as aerial topdressing. Importantly, the aggregate area of cropping land increased, influenced by government support schemes and policy ('domestic support') such as the introduction of the Australian Wheat Board (made permanent in the late 40s). A particularly large increase occurred from the late $50 \mathrm{~s}$ and through the 60s when the combination of the AWB quotas and sustained international demand was operating.

\section{5. $1970-2000$}

With the vast majority of agricultural land relatively young, and progress in all technological factors continuing, the yield increased dramatically from 1970 to 2000 averaging more than $30 \mathrm{~kg} / \mathrm{ha} /$ year toward the end of this period. Søme of the outstanding recent changes and drivers in Australian agriculture are summarised in Table 1. Substantially increased use of nitrogen fertiliser and rotations with canola and other break crops have almost certainly contributed to this increase, while the contribution from better varieties and favourable weather conditions is less certain (Angus, 2001; Poole, 1998; Stephens, 2002). The dependence on nitrogen fertiliser translates to a dependence on fossil fuelsy through the industrial synthesis of ammonia via the Haber-Bosch process (Smil, 2001).

The timeframe of these examples is relatively short when the slowacting nature of some of the key agricultural factors is considered. Consequently, it would be very misleading to extrapolate these trends indefinitely into the long-term future of a sustainable grains industry. The importance of timeframe is particularly evident from the growth in agricultural land, including for cropping (Fig. 3). While there have been large and rapid variations in the area, often associated with shifts to livestock production, the overall trend is for compounding growth at about $2 \%$ per year. While these resources are ostensibly renewable, past growth rates cannot physically continue indefinitely. Should this growth rate be maintained, the area of crop and sown pasture would double in roughly 35 years and within the century it would theoretically encompass half the Australian land mass. Some commentators suggest significant contractions in area may be needed (eg, Hamblin 1996, Meyer in prep.).

The steady increase in land under production has been one of the single most important factors for the past performance of agriculture and grain production in Australia. Evidently a substantial proportion of the compounding growth in production volume (also shown in Fig. 3)

Table 1

Recent rapid changes relevant to Australian cropping, and their possible drivers.

\begin{tabular}{|c|c|c|}
\hline Parameter & Change & Drivers \\
\hline Wheat yield & Long-term average increase $13 \mathrm{~kg} / \mathrm{ha} /$ year, recent trend $30 \mathrm{~kg} / \mathrm{ha} /$ year & $\begin{array}{l}\text { More nitrogen fertiliser for protein content, more Lucerne, canola } \\
\text { and other break crops }\end{array}$ \\
\hline Cereal area & $\begin{array}{l}\text { Inc. } 250 \% \text { in } 25 \text { years from mid } 1950 \text { s } \\
\text { Inc. } 4 \text { Mha mid } 1990 \text { s }\end{array}$ & $\begin{array}{l}\text { Technology, productivity. } \\
\text { Price, productivity. }\end{array}$ \\
\hline Oilseed yields & Inc. $2.5 \%$ pa last 30 years & Varieties, controlling disease, diversification \\
\hline Area oilseed & Inc. $23 \%$ pa last 10 years, inc. $400 \% 1995-2000$ & New canola varieties, profit, disease break, diversification \\
\hline Area legumes & Tripled during 1990s & Soil fertility \\
\hline Area cotton & Inc. $10 \%$ pa last 30 years; inc. $100 \%$ during 1990 s from a high base & Development, investment, cheap water \\
\hline Cotton yield & Inc. $2.4 \%$ pa last 30 years & Pest management, new varieties \\
\hline Water use & $\begin{array}{l}13 \text { years } 1984-1997 \text {. Total water use inc. } 65 \% \text {; NSW, Vic, WA: groundwater use tripled; } \\
\text { irrigation water use inc. } 76 \%\end{array}$ & Cheap water, profit, policy, policy failure \\
\hline Nitrogen fertiliser & Inc. $8 \%$ pa last 20 years & Price premiums for wheat protein, increased wheat area \\
\hline
\end{tabular}



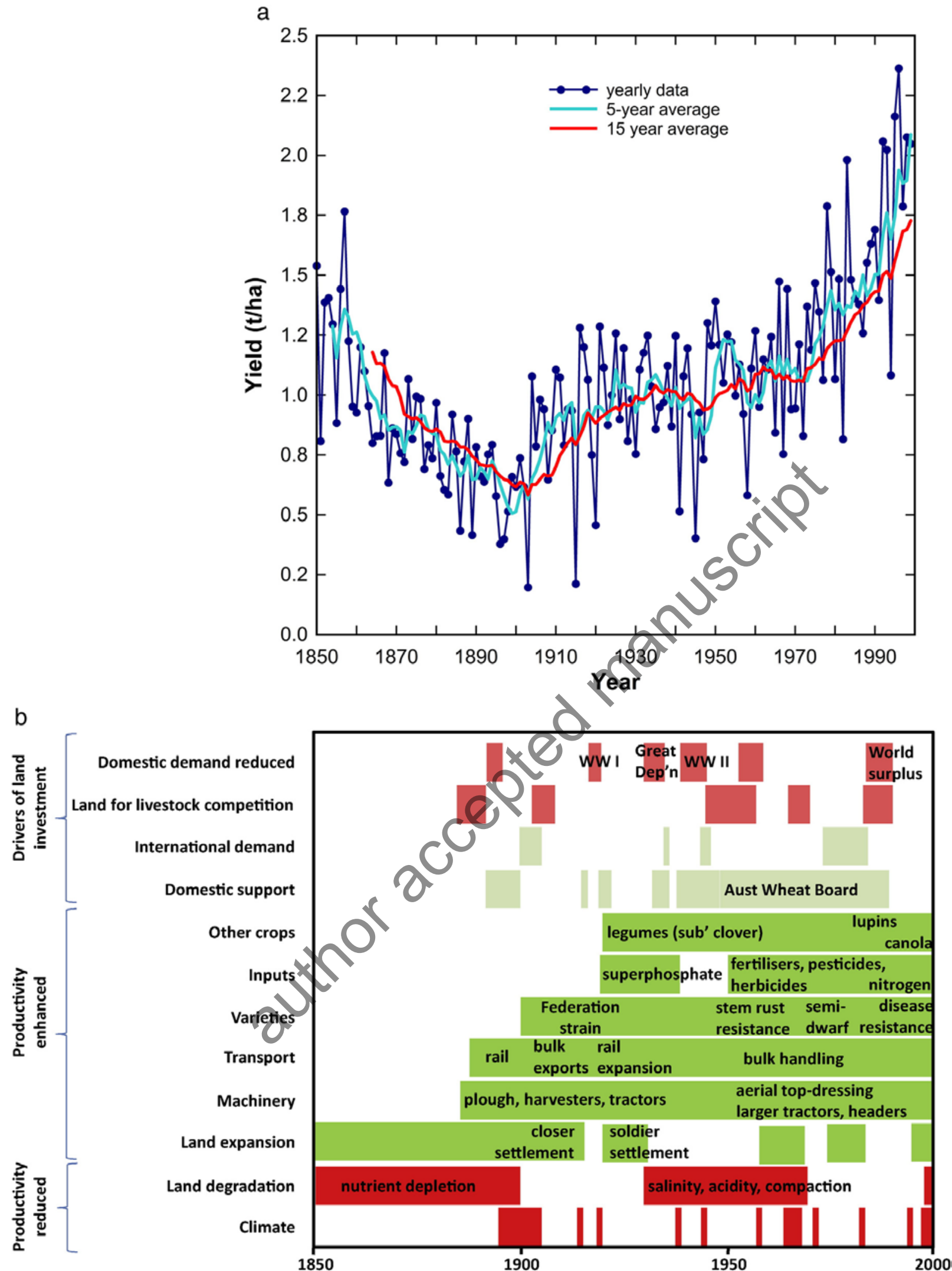

(a) the historical trends in cereal grain yield (predoming

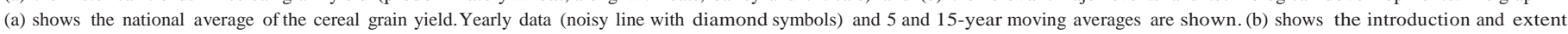

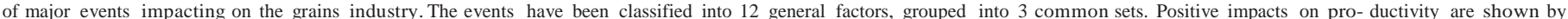
green bars and negative impacts by red bars. (For interpretation of the references to colour in this figure legend, the reader is referred to the web version of this article.)

is directly associated with increasing land area as the strong correlation of volume and area shows (Fig. 3(b)). The growth rate for production is somewhat higher than for cropping area, and the difference is captured in increases of the (average) yield as shown in Fig. 2. Clearly any consideration of the future for the grains industry must tackle what the consequences might be of area increases not continuing. 
a

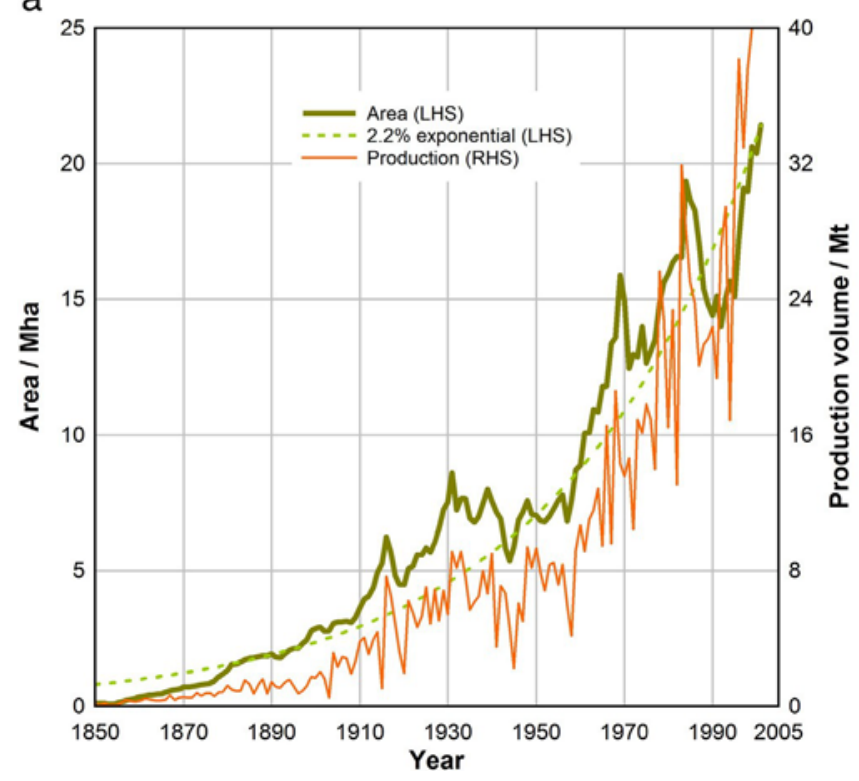

b

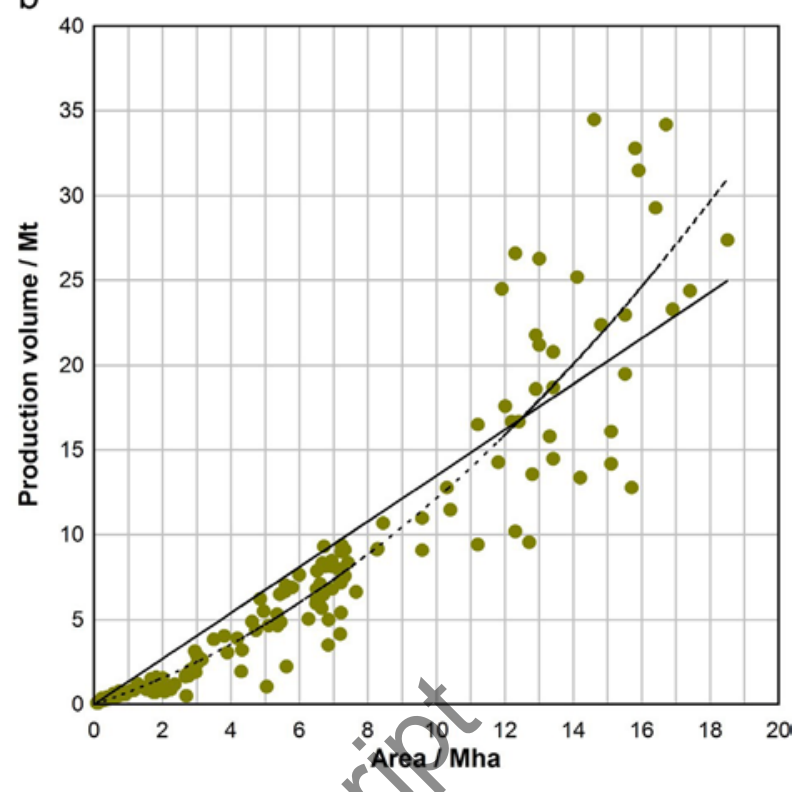

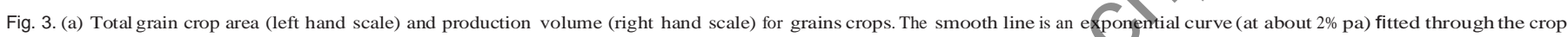
area data. (b) Correlation of cereal volume production and area planted.

\section{Description of the vintaged agricultural cropping model}

From the historical review above it is evident that the agricultural cropping model should incorporate a range of factors that influence crop production and its variation:

- land area, including its age and condition, and transfers between rainfed and irrigated land;

- cropping activity, including the potential for crop rotation and fallowing;

- yield factors that account for land degradation, plant improvements, fertiliser application; irrigation activity; and variations in climate.

This model is one module of a larger capability for studying the physical economy of Australia, namely the Australian Stocks and Flows Framework (ASFF) (Turner et al., 2011), which has been applied to a wide range of sustainability topics. Geographicalty, ASFF covers continental Australia. Agriculture is resolved to 58 regions of relatively homogenous characteristics (statistical divisions, as defined by the Australian Bureau of Statistics, and evident in Fig. 7). The temporal extent of ASFF is long-term: scenarios over the future are calculated to 2100. The model is also run from 1856 with a time step of 5 years, coinciding with Australian Bureau of Statistics census years.

The schematic diagram in Fig. 4 shows the basic structure of the agricultural cropping module in ASFF. (A detailed description of the agriculture model is available elsewhere (Dunlop and Turner, 2003; Dunlop et al., 2002)). This model is used to calculate production of rice, other cereal grains, grain legumes, oil seeds, sugar cane, cotton, vegetables, fruit, nuts, hay, silage and sown pasture in each statistical division. It also keeps track of landscape degradation on both rainfed and irrigated lands. The basic steps are as follows.

- The total area of cropland and sown pasture in each statistical division is accounted for in the dryland and irrigated land stocks. In each time step land can be transferred between the dryland and irrigated stocks, or directly added to, or deleted from, either stock.

- The mixtures of different cropping activities (11 crops, sown pasture and fallow) in each statistical division are specified as proportions of the stocks, 'crop share' in Fig. 4.

- In ASFF the cropping activity is a flow variable, which is calculated as the area cropped per 5 years.
- Landscape degradation is 'evolved' or incremented from one time period to the next. The increments are determined from the areas of the different cropping activities and rates of change per unit of activity that are specified for each activity. (This step is explained in more detail below.)

- Improvements, irrigation, fertiliser, and 'other factors' scale the basic yield.

- The fertiliser yield factor is determined from the intensity (tonnes per hectare) of fertiliser applied to each activity and a fertiliser response function.

- The total amount of fertiliser applied is calculated from the intensity of fertiliser on each activity and the area of each activity.

- Crop and pasture yields are determined from the products of base yields and sets of yield factors that may increase or decrease the base yields. The yield factors represent the effects of loss through landscape degradation, genetic improvements, application of irrigation and fertilisers, and climatic or other variations.

- The total amount of irrigation water use is calculated from the area of each irrigated cropping activity and its respective water use intensity.

Similar levels of modelling are used for the other components of the agricultural sector: feeding animals on grain, hay, silage, sown pasture and rough pasture; producing animal products; and, determining energy, machinery and labour requirements. These are not discussed further here.

\subsection{Age-structuring agricultural land stocks}

An important feature of ASFF is that it keeps track of the age structure or 'vintage' of key stocks throughout a historical period of 50 or more years and the 100-year simulation period. Stocks, including people, cars, buildings and agricultural land are recorded according to the time period in which they were introduced, built or first used. Each such cohort is referred to as a 'vintage' or effectively its birth or creation year e.g., land first cleared for agricultural use in 1890 belongs to the 1876-1891 vintage cohort. The vintaging of land used for cropping and sown pastures is central to the landscape degradation model.

The area of each of the 11 crop types and sown pasture is determined from the additions, deletions and transfers (between dryland and irrigated areas) of the land stock at each time step, combined with the 


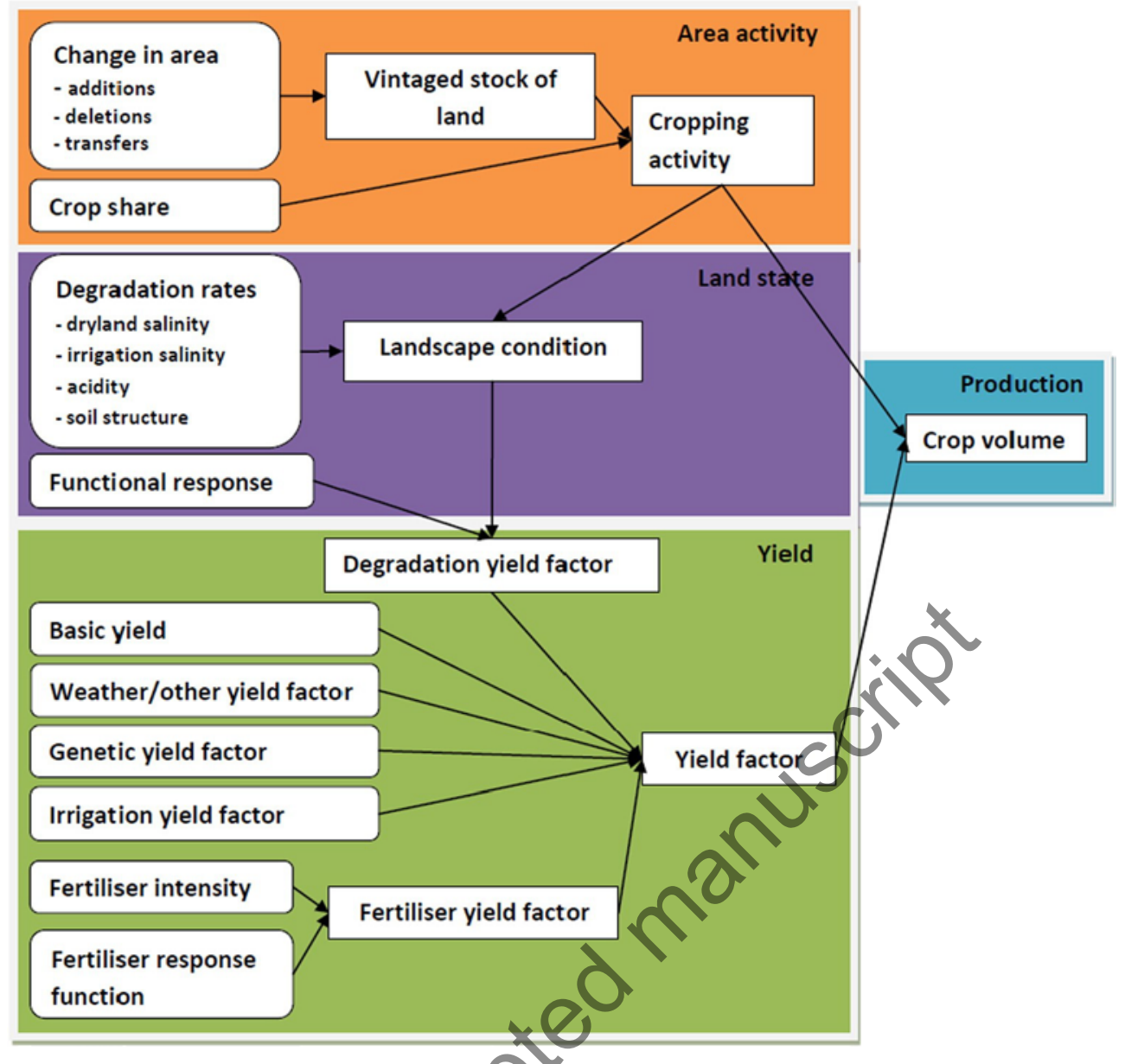

Fig. 4. Schematic diagram of the physical accounting relationships between key yariables of the cropping module. User control variables are shown on the left hand side.

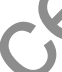

distribution of crops across the total land stock. The land stock is disaggregated into 58 statistical divisions or regions across Australia.

For agricultural land, the first vintage is 1856 , representing all land first cultivated in or before 1856. Each subsequent vintage covers a 5year time period. In a given time period, items in a stock can be deleted from any past vintage, but they can only be added to the current vintage. For example, in the 2006 time period, agricultural land could be retired from any of the vintages 1856, 1861, 1866 and so on through to 2001, but land could only be added to the 2006 vintage.

\subsection{Landscape degradation}

The structure of the landscape degradation model reflects the process whereby land with a longer history of agricultural activity experiences a greater cumulative impact compared with recently introduced land. The model of landscape degradation uses the vintaging concept, not solely to keep track of the area of land in each vintage, but to specify the state of landscape degradation for land in each vintage. Land in each vintage has landscape degradation scores for four parameters: soil acidification, dryland salinity, irrigation salinity, and soil structural decline. Landscape degradation scores are calculated separately for dryland and irrigated agricultural land in each statistical division. The scores are used to calculate yield factors that are equal to the amount by which crop and pasture yields are changed as a result of change in landscape degradation.

Growth in landscape degradation is calculated relative to the condition of land when it was first cultivated or sown, hence all land is given the same initial score ( 0 , since by definition there is no degradation in land not previously used) for each of the four landscape degradation parameters. Intrinsic differences in fertility between regions are accounted for with other yield parameters. All yield parameters in a region are multiplied together (Fig. 4). Land that is added to the agricultural estate (i.e., each new vintage) is given initial landscape degradation scores of zero which translate to no loss in yield. Further landscape degradation is indicated by increasing scores with a maximum of 100 . Similar scores for land in different statistical divisions does not imply that the land is equally productive, rather that the different areas have undergone similar changes in landscape degradation relative to their initial states.

In each time period the landscape degradation scores for each vintage are changed by increments that depend on the mix of agricultural activity. Separate increments are calculated for dryland and irrigated land in each statistical division. Each activity has a propensity to alter each of the four landscape degradation modes. The propensities or 'rates of change per unit activity' can vary among statistical divisions, agricultural activities, dryland and irrigated land, and the four landscape degradations (and their calibration is described below). For example, cereal cropping is likely to contribute to dryland salinity in southwest Western Australia more so than in the Darling Downs; and, legume crops are more likely to contribute to soil acidification than cereal crops. The landscape degradation score in each statistical division, is incremented by the average of the rates of change of all the activities (weighted by the relative areas of each activity). The increments can change over time as the mix of activities changes. The rates of change per unit activity can also change over time to represent changed management, for example, the adoption of agricultural systems that are less acidifying or that contribute less to soil structural decline. Negative rates of change in the model are used for activities that reverse degradation and lead to improvement in the landscape function. 
In a given statistical division the increments calculated from the agricultural activity in each time period are added to the landscape degradation scores from the previous time period. The increments are the same for all vintages in a statistical division, but younger vintages will have experienced fewer increments than older vintages hence they will tend to have lower landscape degradation scores. This represents the greater cumulative effects of agriculture on land with a longer agricultural history.

\subsection{Yield response to degradation}

The four landscape degradation scores are used to calculate four yield factors which are multiplied together to produce a single 'landscape degradation yield factor' for each vintage. This yield factor is the fraction by which yield is reduced due to loss through landscape degradation. The landscape degradation yield factors are then combined with a base yield and yield factors for other components of the agricultural system (genetics, irrigation, fertiliser, weather/other) and the areas of different activities to calculate crop and pasture production in each statistical division.

The relationships between the landscape degradation scores and the yield factors are determined by 'yield response functions' (Fig. 5). Calibration of these functions is explained in the following section. A large amount of information exists about various growth responses of different species to various physical and chemical soil properties at different growth stages under different growth regimes, but there are no data that relate crop yield responses to land degradation at the regional or statistical divisional scale. Part of the reason for this lack of data is that measured yield parameters that vary within any given region. Also, as noted earlier, variation over time in other regional-scale land use and productivity factors makes it virtually impossible to measure any such relationship between yield and degradation. However, these factors do not mean that well defined, underlying empirical relationships between yield and land degradation at the regional scale don't exist, if they could be measured practically.

Due to the lack of measurement we had to make assumptions about the end points of the relationship and its overall shape. When there is no degradation there is no loss in yield, so the yield response curves all have a yield factor of 1 (no change) for a landscape index of zero (the initial value). At the other extreme, when salinity and soil acidification are at their worst crops cannot grow and yield will be zero. Soil structural decline is very variable but many types inhibit plant growth rather than preventing it, hence some yield (say 25\%) may be likely when it is at its worst across a region. So for scores of 100 (worst degradation) we can set the salinity and acidification yield factors to zero and the structural decline yield factor to 0.25. Finally, we assume some type of logistic or "S-shaped" response curve since many of the detailed processes leading to loss in yield have thresholds and non-linear responses (e.g., water tables can rise many metres with no effect until they come close to the root zone). The calibration process described below effectively determines the slope of this function. (Using an alternative linear response function proved to be incompatible with the calibration process.)

\subsection{Scale and aggregation}

Landscape degradation is evident at a coarse national scale: across Australia millions of hectares of land are affected which would not be had they not been used for agriculture (Pratley and Robertson, 1998). However, the biophysical processes that have led to this degradation occur at a local scale and are highly variable. The processes are frequently patchy in space and episodic in time. As well, they can be non-linear, involving thresholds, hysteresis and feedbacks. Some of the processes occur slowly, e.g., dryland salinity and soil acidification, and it can take generations before gradual decline becomes a well established problem. Some of the processes can only be understood in three or four dimensions, for example, dryland salinity involves water flows down through the soil in some places, horizontally transmitted changes in water pressure and upward flows some time later in a different location. There are interactions between the processes. For example, while increasing acidity can cause clay particles to flocculate and improve soil structure, it decreases water uptake by roots, potentially leading to greater recharge and increasing dryland salinity.

Our simplified approach is required given the lack of data and the sheer volume of local-scale data and computer processing that would be required to sum local-scaled processes up to the regional level. In addition, it is not always clear that our understanding of the processes is good enough to aggregate local-scale information to explain and predict regional outcomes (Hatton, 2000). While at a small scale (10,000 ha) there is evidence of loss of production and changes in land use as a result of land degradation, land use and productivity changes driven by other, larger-scale factors make it very difficult to determine the impacts of land degradation at regional scales (Walcott, 2001). Nonetheless, estimation of this larger-scale information is needed both for assessing management options and to inform the development of regional, state and national scale policy.

Our approach to modelling these biophysical change processes at a large scale is to mimic the broad-seale empirical correlations or emergent features of the small-scale processes using relatively simple model structures. This approach is conceptually simpler and based on empirical data at the seale of the model rather than any actual or implied understanding of the underlying processes. As such, it is relatively transparent and assumption free. Model parameters may be quite different from those of models that actually describe the details of the processes, and their calibration is likely to be straightforward but limited by the availability of trend data at the relevant (larger) scale.

\section{Calibration of the model}

A wide variety of data from many different sources was used to calibrate the agricultural cropping model (further details are available in (Dunlop and Turner, 2003)). A primary data source for recent decades (1983-1997) on cropping area and production volumes for a detailed list of commodities was the Agricultural Statistics made available by the $\mathrm{ABS}^{2}$ and the Australian Commodity Statistics from ABARES. ${ }^{3}$ A significant source of longer term data, extending back to 1850 was obtained from the Australian Historical Atlas (Camm et al., 1987). Common calibration tasks involve resolving discrepancies ("harmonising"), aggregation and disaggregation, interpolation and extrapolation, and imputing values for unknown parameters. The original calibration was completed to 2001 (and is currently being updated). The elapsed decade since then provides an opportunity to validate the model against independent data, as presented later.

\subsection{Age-structuring land stocks}

Having established the land area and the cropping activity share over the complete historical time period, the process of determining the vintage of the land stocks was a relatively simple matter of taking the difference between areas at consecutive time-steps, allowing for potential reductions. Data on retirement of agricultural land was not available, and was assumed to be negligible in the past since most cleared land remains in the agricultural system, possible left idle.

Across Australia, at the end of the history period (2001) about $25 \%$ of agricultural land was first cultivated within 30 years, $45 \%$ is 30 to 50 years old and $30 \%$ is more than 50 years old (Fig. 6). Despite the

\footnotetext{
${ }^{2}$ http://www.abs.gov.au/AUSSTATS/abs@.nsf/ViewContent?readform\&view= ProductsbyTopic\&Action=Expand $\&$ Num $=3.1 .4$.

${ }^{3}$ http://www.daff.gov.au/ABARES/pages/publications/pubs.aspx?url=http:// 143.188.17.20/anrdl/DAFFService/pubs.php?seriesName=AustCommodities\%26sort= date\%26sortOrder $=$ desc\%26showIndex $=$ true\%26outputType=list\%26indexLetter $=$
} 
Table 2

Estimates of the fraction of yield lost to each form of degradation for the nation as a whole at about 2001. These losses are the targets of the calibration process.

\begin{tabular}{lllll}
\hline & $\begin{array}{l}\text { Soil } \\
\text { acidification }\end{array}$ & $\begin{array}{l}\text { Dryland } \\
\text { salinity }\end{array}$ & $\begin{array}{l}\text { Irrigation } \\
\text { salinity }\end{array}$ & $\begin{array}{l}\text { Soil structural } \\
\text { decline }\end{array}$ \\
\hline Proportion of yield lost & $4 \%$ & $2.4 \%$ & $3 \%$ & $3 \%$ \\
\hline
\end{tabular}

Table 3

Rates of change in landscape degradation per unit activity (hectares planted per 5-year time step) for each crop type, expressed relative to cereal grain. These relative rates are inputs to the calibration process to determine the absolute rates of change, as explained in the text.

\begin{tabular}{|c|c|c|c|c|}
\hline \multirow[b]{2}{*}{ Crop type } & \multicolumn{4}{|c|}{$\begin{array}{l}\text { Rate of change in landscape degradation score, relative to } \\
\text { cereals }\end{array}$} \\
\hline & $\begin{array}{l}\text { Soil } \\
\text { acidification }\end{array}$ & $\begin{array}{l}\text { Dryland } \\
\text { salinity }\end{array}$ & $\begin{array}{l}\text { Irrigation } \\
\text { salinity }\end{array}$ & $\begin{array}{l}\text { Soil structural } \\
\text { decline }\end{array}$ \\
\hline Cereal grain & 1 & 1 & 1 & 1 \\
\hline Legume grain & 3.3 & 1 & 1 & -1 \\
\hline Oil seed & 1.4 & 0.8 & 0.8 & 1 \\
\hline Rice & 0 & 1 & 2.0 & 1 \\
\hline Cotton & 1.1 & 0.8 & 0.8 & 1 \\
\hline Sugar cane & 1.9 & 0.5 & 1 & 2 \\
\hline Vegetables & 0.8 & 0.5 & 1 & 0 \\
\hline Fruit & 1.1 & 0.2 & 0.5 & 0 \\
\hline Nuts & 0.7 & 0.2 & 0.5 & 0 \\
\hline Sown pasture & 1.1 & 1.5 & 1 & -0.5 \\
\hline Hay & 2.2 & 1 & 1 & -0.5 \\
\hline Silage/green feed & 2.2 & 1 & 1 & -0.5 \\
\hline Fallow & 0 & 2 & 5.0 & 1 \\
\hline
\end{tabular}

fact land was first cleared for agriculture 200 years ago, most of our crop and sown pasture land is less than 40 years old. Since retirement of agricultural land has not been significant to date, the current age structure simply reflects the amount of land added to the agricultural estate in each time period.

\subsection{Calibrating the landscape degradation functions}

The key challenge in the calibration was to derive the degradation rates of change per unit activity in each region i.e., statistical division. While the National Land and Water Resources Audit made substantial progress in improving the quality and coverage of national mapping of land degradation, there is very little large-scale information about the severity of land degradation in terms of its impact on crop and pasture production. Information about the severity of land degradation is most commonly published in terms of cost of degradation due to loss in gross value; for example, (CRCSLM, 1999) estimated that soil acidity costs $\$ 700$ million in lost production, and (PMSEIC, 1998) reported that dryland salinity costs $\$ 130$ million in lost production. Such figures come from a variety of sources, are seldom documented and probably vary greatly in quality, but basically they are the only published national-scale estimates of the severity of land degradation.

The following information was used to derive the rates of change of landscape degradation per unit activity for each activity in each statistical division.

- The history of cropping activity in each statistical division from 1856 to the present (as described above);
- yield response functions (as described above);

- estimates of the proportion of national yield lost to each type of degradation (Table 2) based on ratios of the published figures for the value of lost production and the gross value of production of those crops likely to be most affected by degradation;

- estimates, for each type of degradation, of the relative extent of land affected in each statistical division. The dryland salinity and irrigation salinity data were derived from NLWRA digital coverages of areas at risk of salinity and land use. The soil acidification and soil structural decline data were derived from various published and unpublished maps (Dunlop et al., 1999b), then revised following an expert workshop (Dunlop et al., 1999a);

- estimates for each statistical division of the yield lost due to each form of degradation were derived from the data described in points 3 and 4 above and the area of crops and sown pasture in each statistical division. Effectively the spatial information was used to spread the national yield loss among statistical divisions (Fig. 7); and

- relative rates of change for each crop type (Table 3) which were derived from the literature on changes in landscape degradation at fine scales.

An iterative parameter fitting routine was used to derive absolute rates of change of landscape degradation per unit activity (e.g., Table 4 for cereals) such that

- when these rates were applied to the cropping history (point 1, above),

- and the yield response function specified in point 2 was used,

- the losses in yield at the end of the history period (2001) were equal to those specified in point 5 ,

- stubject to the constraint that the ratios between the rates of change conform to those specified in point 6 .

Separate rates of change were derived for dryland and irrigated activities, with the same target yield losses (point 3) except that irrigation salinity was set to zero for dryland activities. The iterative routine converged when using the logistic yield response function described above, but not when using a linear function. The calibration procedure assumes that the rates of change per unit activity have not varied significantly over the history period. The time-invariant rates of change in landscape degradation for cereal grains derived from the calibration procedure above are given in Table 4 . If information about the changing rates of degradation were available then it could be included as an input to the calibration process. Similarly, projected time variations in scenario settings can be incorporated, where such variations are justified. With the exception of the ratios of the rates of change per unit activity, this calibration process did not require any scaling up of parameters from local scale processes: all of the information used was at the statistical division scale.

\subsection{Other factors}

Other yield factors, acting in combination with the landscape degradation yield factor, were either specified or imputed in the calibration process (Fig. 8). Irrigation was assumed to approximately double cereal yields, while plant improvements (labelled 'genetic') were assumed to

Table 4

Rate of change of the four landscape degradation modes per unit cereal grain activity, determined by the calibration process explained in the text (cropping activity is specified as hectares per 5-year time step. Units for rates of change are landscape-degradation-score (as Fig. 5) per 5-year time step.).

\begin{tabular}{|c|c|c|c|c|}
\hline \multirow[b]{2}{*}{ Crop type } & \multicolumn{4}{|c|}{ Rate of change in landscape degradation score per hectare crop activity in 5-year interval } \\
\hline & Soil acidification & Dryland salinity & Irrigation salinity & Soil structural decline \\
\hline Cereal grain & 0.85 & 0.50 & 1.16 & 6.75 \\
\hline
\end{tabular}




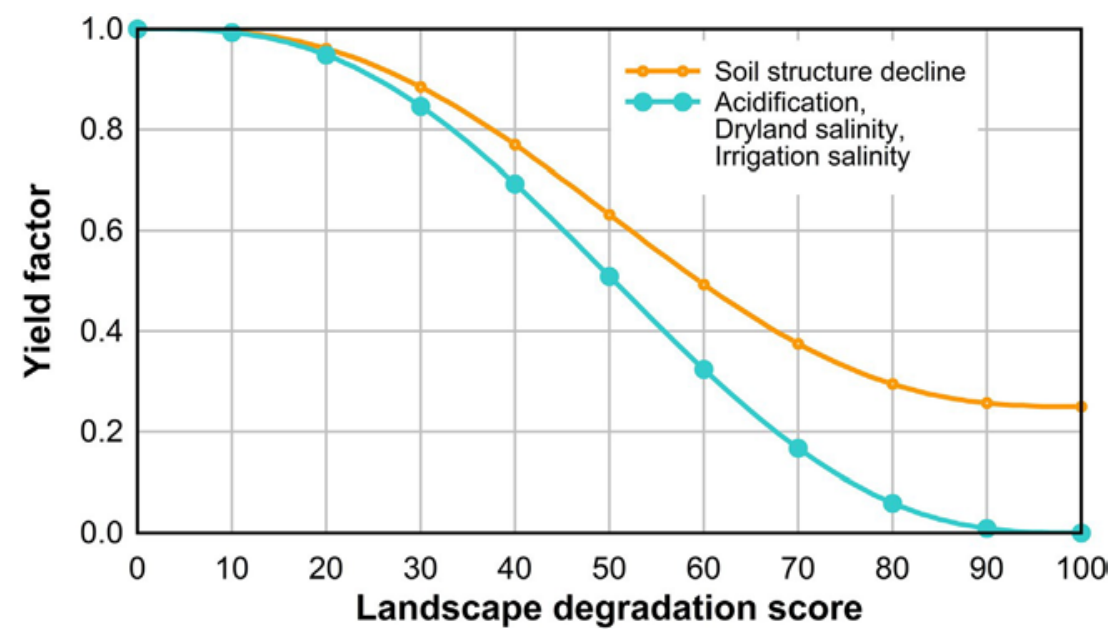

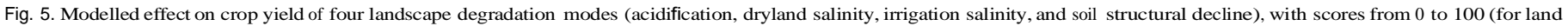

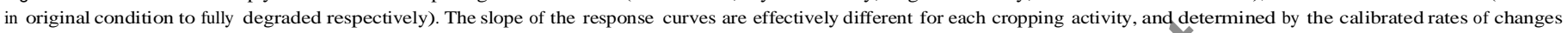
per unit activity (Table 4).

increase yield by about $70 \%$ from 1900 to 2000 . Yield enhancements through application of fertiliser was imputed to increase over time, as volumes applied increased, but moderated by a fertiliser response function which saturated at about a factor of 3 for $1 \mathrm{t} / \mathrm{ha}$ of fertiliser applied. Basic yield ( $\mathrm{t} / \mathrm{ha}$ ) and the factor accounting for weather variability or other factors were imputed as the remaining constant and timevarying residuals, respectively.
The weather/other factor shows a decline over the four decades to 1900, which apparently accounts for soil nutrient depletion prior to the advancements subsequently made in wheat strains and other farming techniques. An increase in the weather/other factor for the last 2-3 decades of the historical calibration may indicate an underestimate of yield improvements in other factors, such as genetic gains.

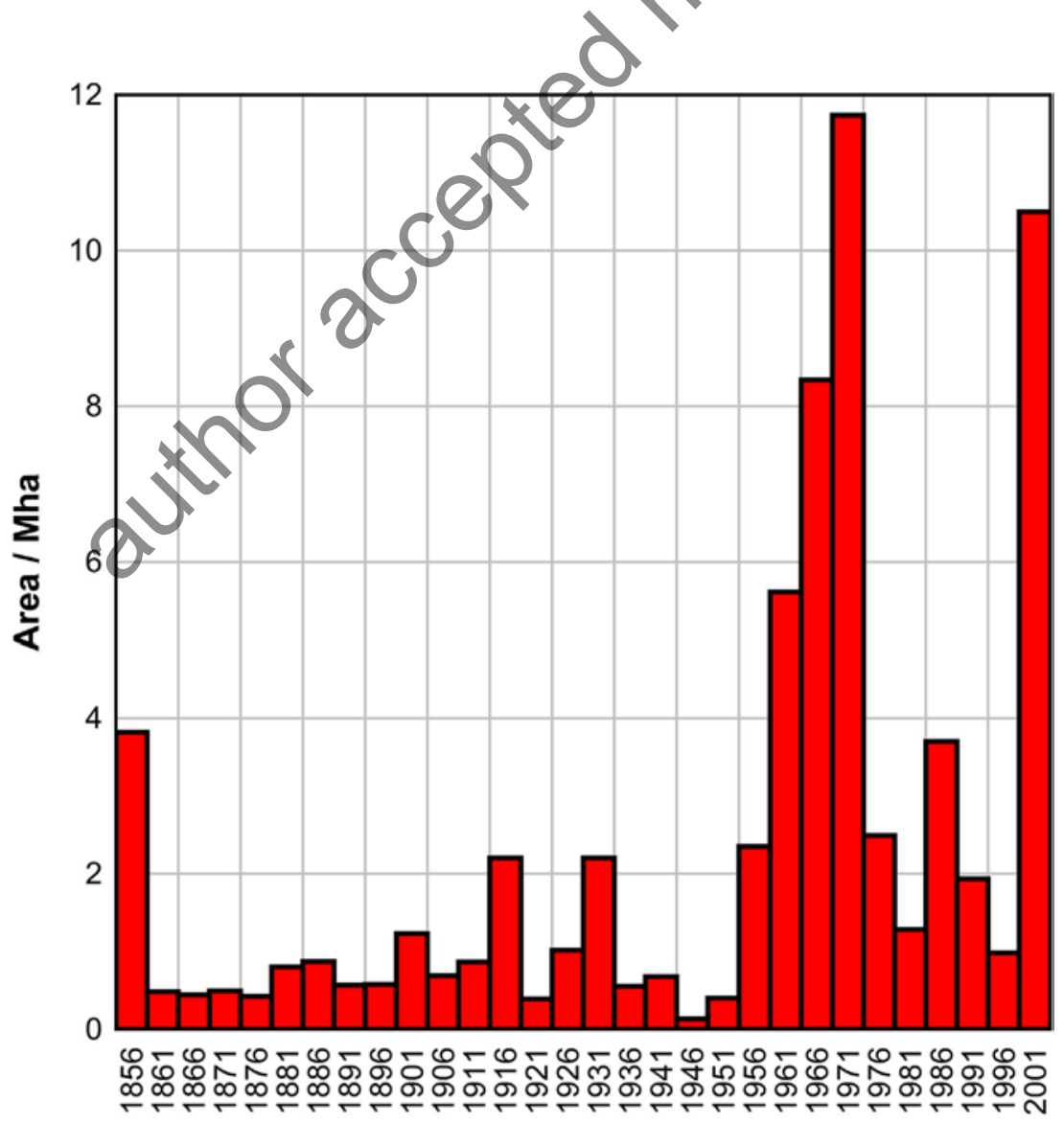

\section{Year}

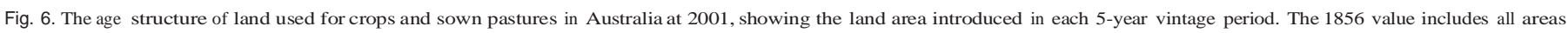
added prior to 1856 . 


\section{Simulated outcomes for the long-term historical period to 2001}

Operation of the agricultural cropping model over the historical period reproduces crop production volumes, as well as requirements for inputs such as water and fertiliser. It also provides a detailed perspective on the role of ageing and landscape degradation as a significant factor in the final yield that is realised.

\subsection{Land age and landscape degradation}

Throughout most of the last 150 years, about one-third of the land in cultivation has been less than 20 years old, and at least half has been younger than 40 years old (Fig. 9a). This is a direct consequence of the compounding growth rate of land additions. However, for a period shortly after 1930 the agricultural land aged quickly, reaching a peak in the 1950s. This ageing was the result of the land area remaining relatively constant over this period. Subsequently, rapid expansion from the late 1950s reversed the ageing trend.

Also shown on Fig. 9a is the 15-year average yield (reproduced from Fig. 2) at each 5-year time-step of the historical simulation. The 3 decades from 1930 when the agricultural land was relatively old corresponds with the period when yields had reached an approximate plateau (or two slightly different plateaus). During this period, significant technological advances were introduced to Australian agriculture and cropping, as described above; nevertheless, yields did not significantly improve.

Degradation commonly appears to begin impacting yield after a vintage of land has been in production for about 40 years, and that parcel of land enters the downward slope of the yield response curve (Fig. 5). Despite this, the correlation (Fig. 9b) between the relative change in average yield and the proportion of land older than 40 years (averaged, as for yield, over the preceding 15 years) is not statistically strong, due to the influence of independent factors such as climate variation and other yield

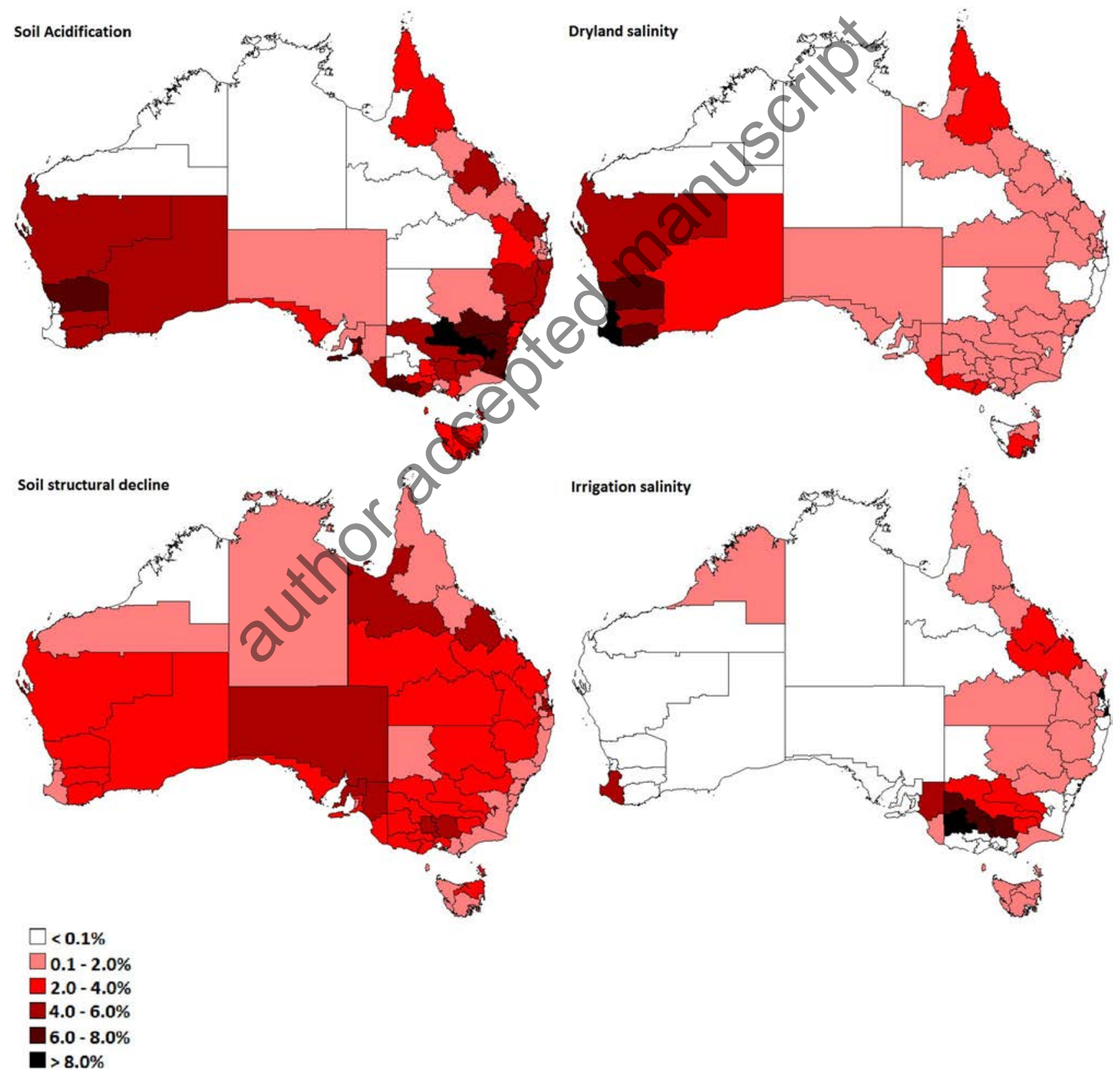

Fig. 7. Geographical distribution (at statistical divisions) of percentage yield loss at 2001 for each of the four landscape degradation modes, derived from national yield loss data and geographical data on agricultural activity. 


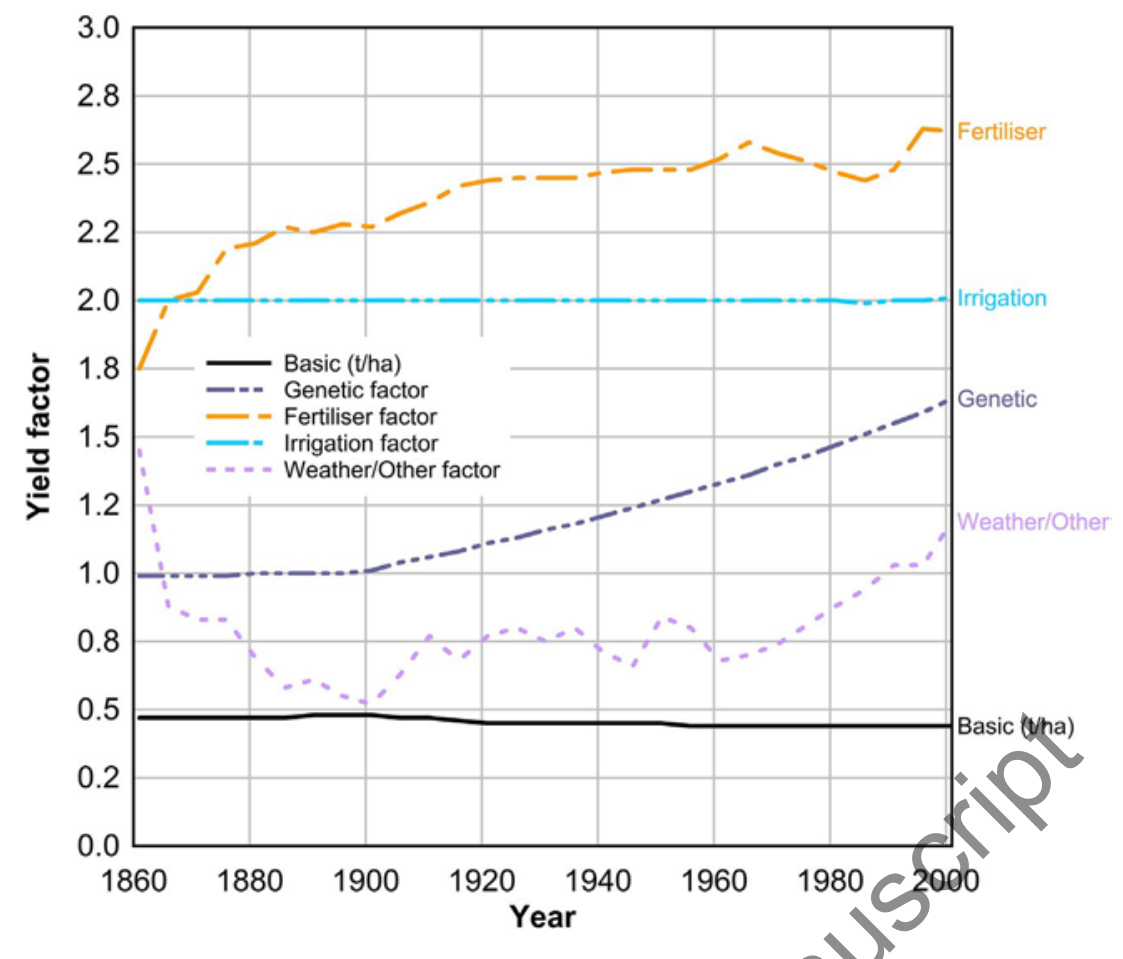

Fig. 8. National (area-weighted) average yield factors (other than land condition) for cereals. Basic yield is in tonne/hectare, while other factors are unit-less multipliers.

factors (Fig. 8). This is particularly evident when the land stock is about evenly divided between young and old (N40 years) vintages.

Actual degradation is also spread across all vintages, and not simply associated with one particular age threshold. The frequency distribution of landscape degradation (Fig. 10) shows the areas of crop and sown pasture where yields are reduced due to loss of landscape condition in 1901, 1951 and 2001. In the early period, all of land is unaffected or only marginally affected. Later, when these relatively small areas have been in production for many decades, the degree of yield loss becomes substantial, reaching up to 50\% in 1951 and even 90\% in 2001. However, the additions of substantial areas of new land (Fig. 6) have reduced the net impacts of yield losses caused by gradual fertility decline and

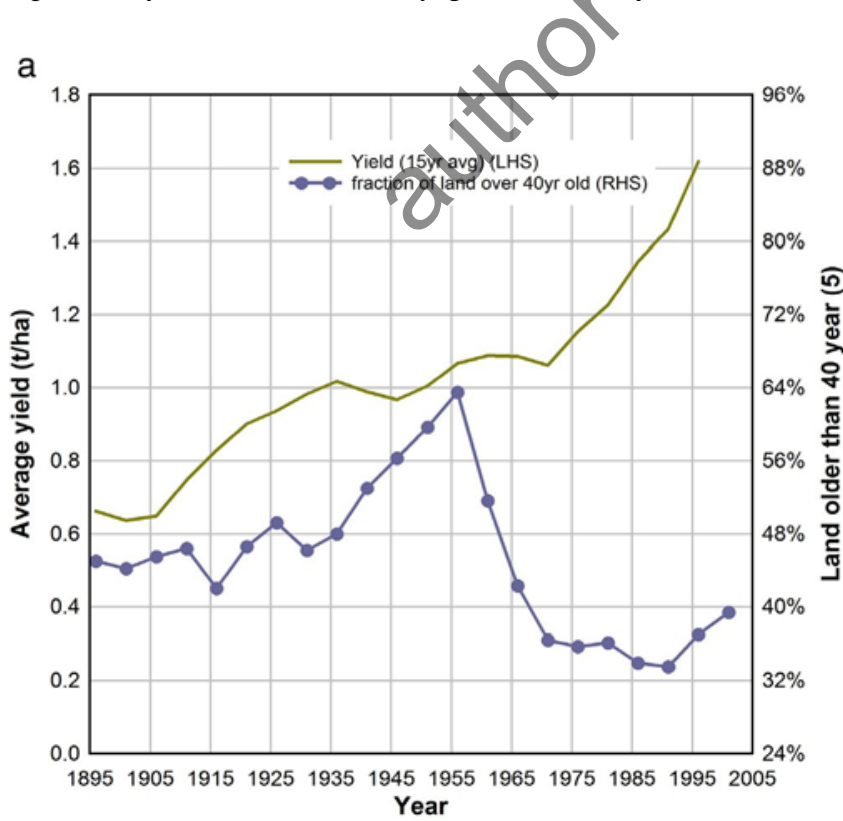

degradation of land that had been in use for an extended time. The dynamics are not geographically homogenous-in a number of regions there was a marked increase in effect of degradation on yields once the area being cultivated stopped increasing.

Similarly, there have been temporal changes in the simulated landscape yield loss over the historical period (Fig. 11), with the compounding growth of the early 20th century interrupted and reversed at about 1950 for two decades. The yield losses of Fig. 11 are national averages obtained by weighting the spatially disaggregated yield loss for each vintage parcel of land by the area of that parcel. An area-weighting is also applied to each degradation type in order to combine each into an overall yield loss (which is therefore not the sum of the four curves). On this basis, the

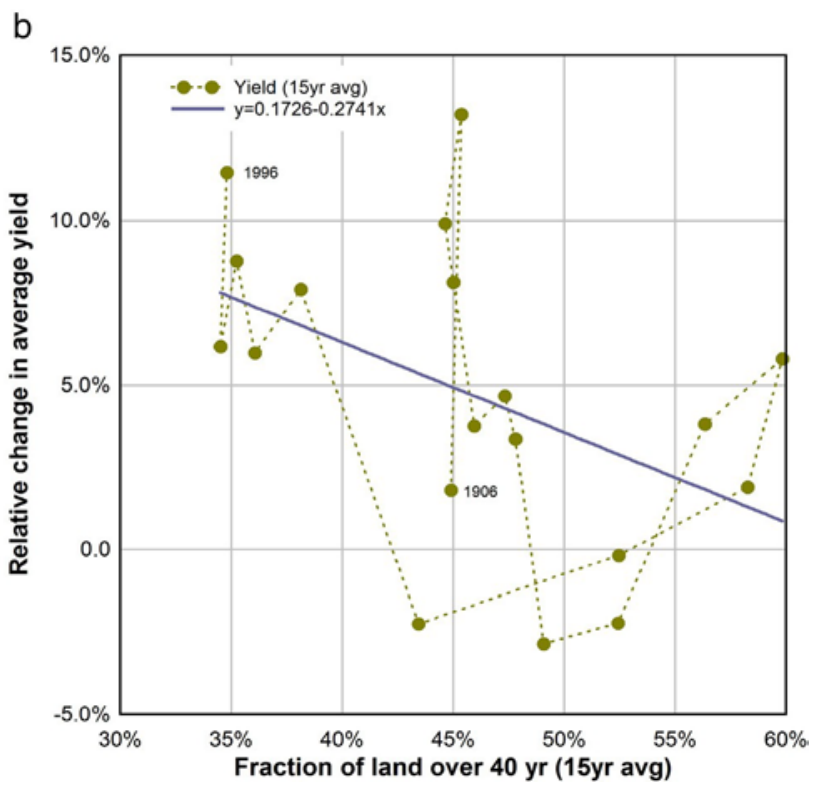

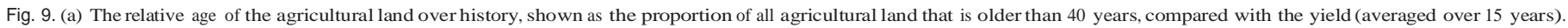

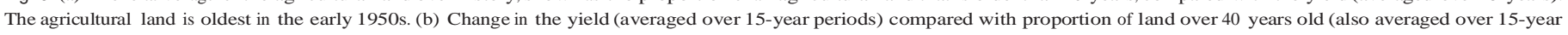
periods). 


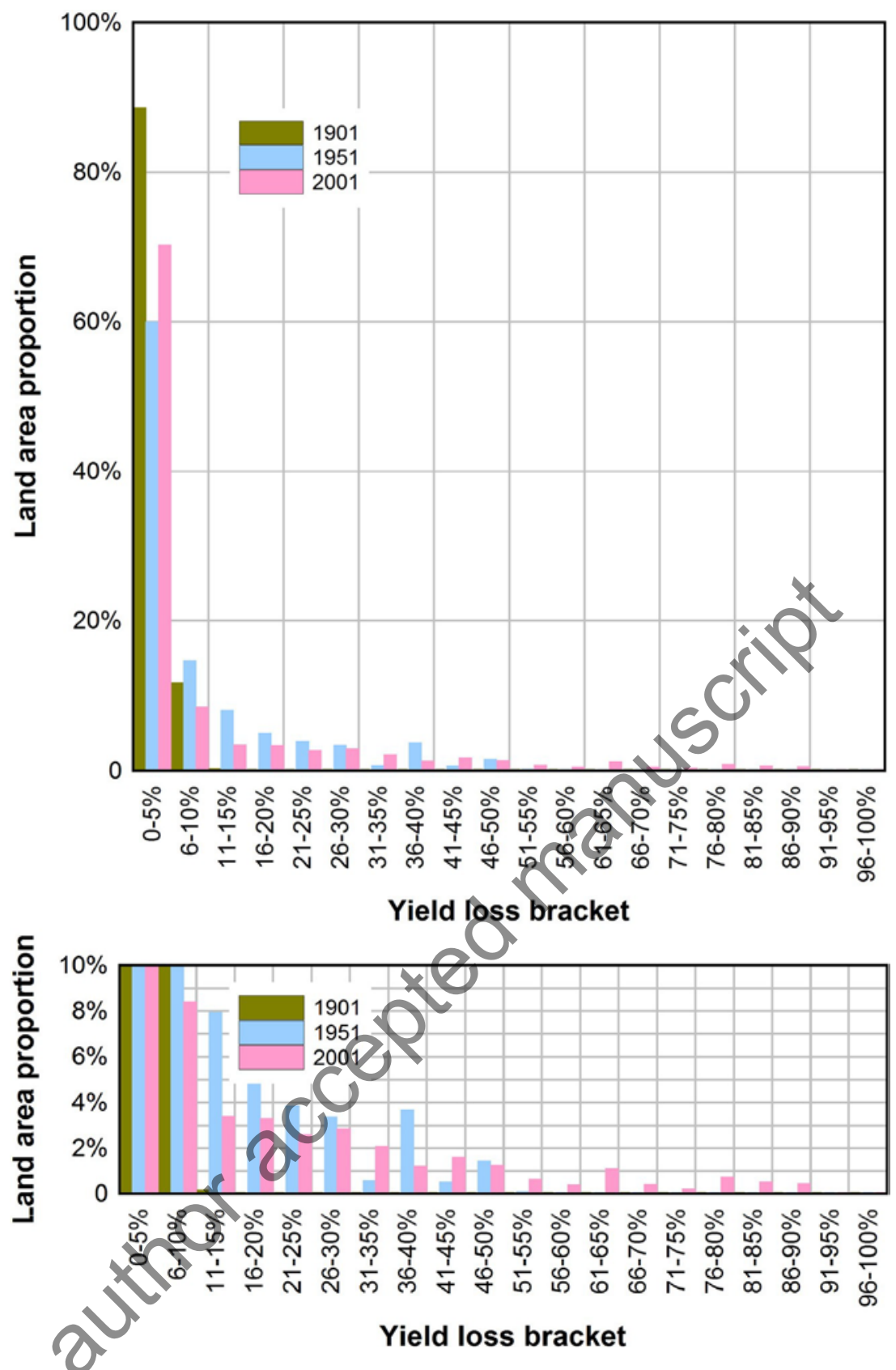

Fig. 10. The frequency distribution of landscape degradation yield loss for three years $(1901,1951,2001)$ in the history calibration (expanded scale provided for the distribution for yield loss greater than $5 \%$ ).

average overall loss in yield is about $9 \%$ at the end of the historical period. Fig. 11 also confirms that the yield loss in 2001 simulated for each of the four conditions is as specified in the calibration process (Table 2).

Simulated national cereal yield (production/area) reproduces the observed data (Fig. 2a), except for early history to 1900, where it increases from a lower value to the 1900 figure. This occurs because the historical simulation was initiated in the mid-1850s with a relatively large 'burst' of new un-degraded land added at this time to account for the existing land from earlier years (Fig. 6). Hence the simulation does not recreate an initial ageing of the land, which would produce a decline in yield (that is absorbed in the weather/other yield factor see Fig. 8). In principle, this also means that the degradation for these vintages is underestimated later in the historical simulation. However, these vintages constitute a very small proportion of the cumulative land total due to the overall $2 \%$ pa expansion, and hence they do not unduly influence the aggregate outcome of production and yield.

\subsection{Comparison of model results with recent crop production}

Validation of the model (calibrated to 2001 due to project constraints) with independent data was undertaken with recent cropping data provided to 2011 (i.e., two 5-year timesteps). A longer validation period was not created by artificially reducing the calibration period since this would produce a more inaccurate model, though future research could explore this relationship. The data describes both the annual production volume and area of cropping (at least at State level and partially for Statistical Divisions). The area data was used as input to the model; all other inputs were held constant after 2001; in particular, the weather/other yield factor was initially set at the average of the preceding 30 years. Simulated production of cereal grains reproduces the observed volumes within about $10 \%$, which is well within the uncertainty range associated with weather-related fluctuations (Fig. 12). 


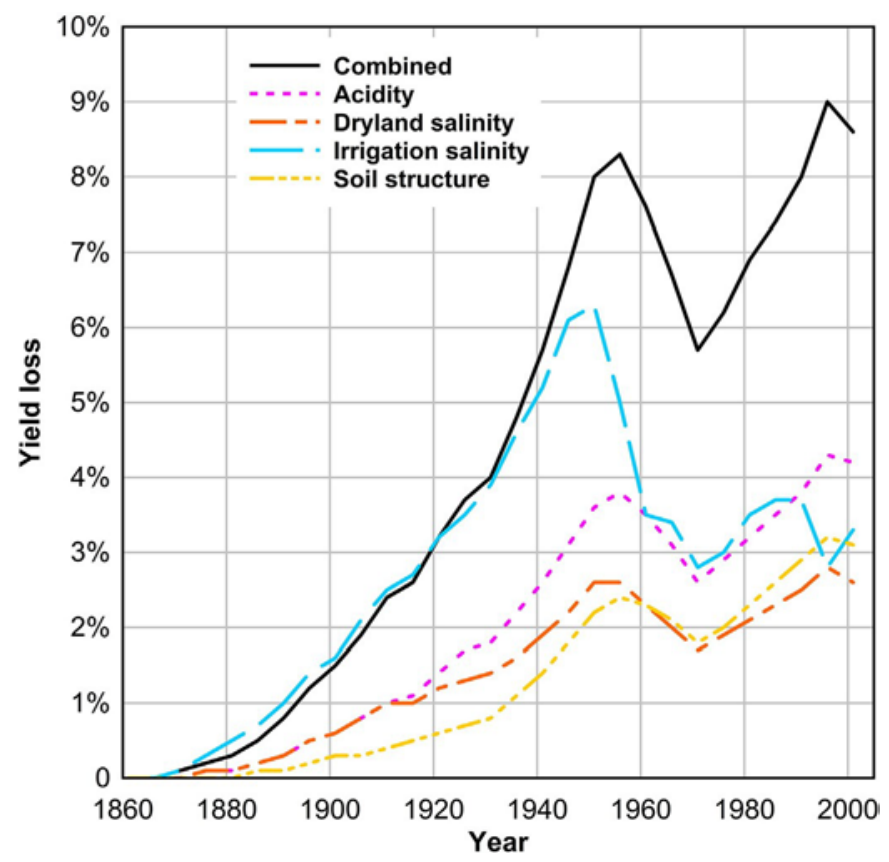

Fig. 11. Average (area weighted) percentage yield loss due to the four land degradation types, and overall yield loss from their area-weighted combination.

Both simulated and observed production volumes do not show the increase in volume expected with increase in cropping area (Fig. 3). It is relatively uncommon throughout the 150 year history for production to fall or stagnate while cropped area increases. In the validation period, this is most likely due to climatic conditions when Australian agriculture suffered the effects of the 1997-2009 Millennium drought (BoM and CSIRO, 2014). This appears reflected in the large fluctuations of the annual production volumes (and large uncertainty range). Confirmation of the short-term importance of climatic conditions is provided by using

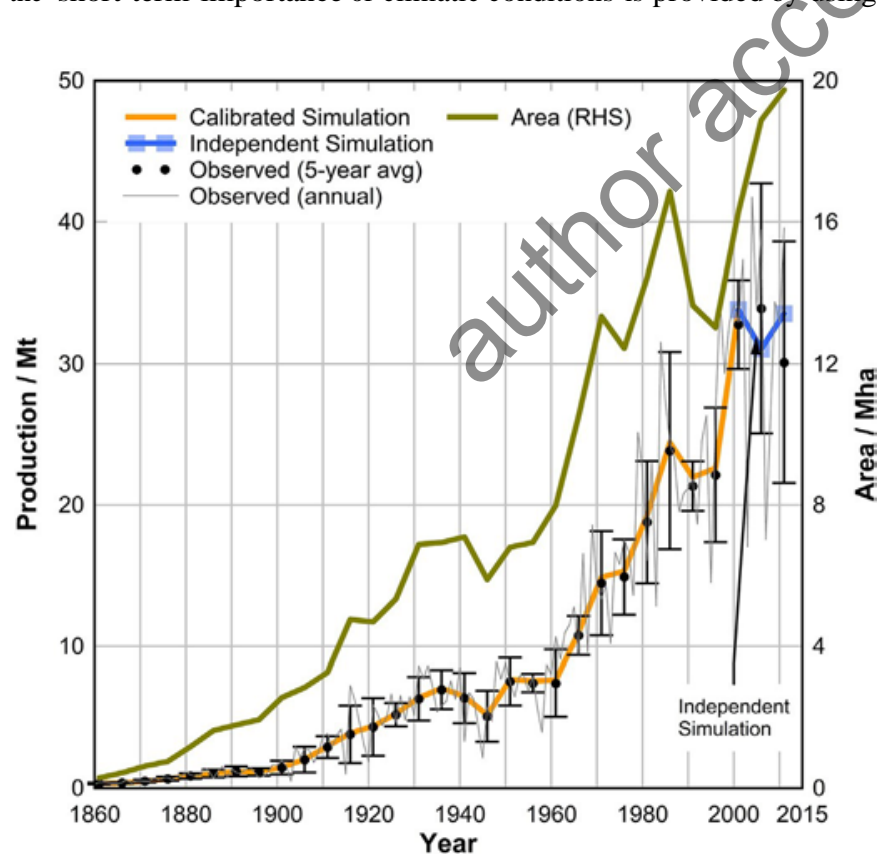

Fig. 12. Comparison of simulated cereal grain production with observed data (thin line shows annual data; solid circles with standard deviation error bars show 5-year averages). Simulated production is calibrated to the observed data up to 2001. Beyond this, independently simulated 5-year production for 2006 and 2011 (square symbols with blue line) is close to observed production. Area of cereal grain cropping is also shown (RHS). (For interpretation of the references to colour in this figure legend, the reader is referred to the web version of this article.) alternative settings in the validation period for the weather/other yield factor. Using either the yield factor of 2001 or an average over the entire history period results in simulated production volumes at the upper and lower values of the uncertainty range, respectively.

The roll of land degradation in the output of the validation period is likely to be limited since it is masked by recent and earlier increases in cropping area. This is despite our expectation for the negative effects in the model of dryland salinity to be somewhat over-estimated due to reduced rainfall leading to lowered soil water table levels. We note that validation of the degradation model is also limited because this period of only two time-steps is insufficient for significant degradation processes to impact yield.

\subsection{Implications for future scenarios of the Australian cropping industry}

The future of Australian agriculture and cropping is likely to be significantly different from the past, not least because projecting expansion forward at the long-term $2 \%$ pa rate would theoretically overrun the Australian landmass in about a century. Additionally, issues such as the emission of greenhouse gases associated with land-clearing, availability of scarce water resources, poor quality soils (CSIRO, 2009), and the requirement for fertilisers and other mineral inputs would also act as constraining factors on the potential for expansion into northern Australian. Consequently, it is necessary to explore the implications of alternative futures for Australian agriculture. We present an illustrative situation where land area and activity is held constant at the 2006 extent, with no additions or deletions made in the agricultural model throughout the scenario period to 2101.

The resultant ageing and degradation process of stabilised land activity is evident in the frequency distribution of yield loss (Fig. 13), such that by the end of this century virtually all land is impacted significantly and there is a relatively even distribution of loss. Both the area of Rand impacted by landscape degradation loss and the associated yield loss increase rapidly (Fig. 14). The latter grows at a rate commensurate with 1950 changes and reaches about 25\% by mid-century.

\section{Discussion}

It is evident from these results that in Australia crop yield loss is significant due to land degradation and will become more significant over time. On a global scale, significant yield loss in one food bowl would not be a serious problem. However, land degradation is recognised as one of the most pressing global environmental, economic and security issues (Dent et al., 2007). Although the causes, severity and extent of land degradation are only roughly known, and in some cases disputed (de Jong et al., 2011), there is consensus that it is widespread (Okin et al., 2001). It can also be self-accelerating, so the cost of rehabilitation rises exponentially as it advances (Glantz and Orlovsky, 1983) to the extent that it may be irrecoverable on a human timescale at manageable cost (Okin et al., 2001). In some forms, it also has a reciprocal relationship with climatic systems (Schlesinger et al., 1990; Prospero and Lamb, 2003) causing significant changes in global biogeochemical cycles.

To meet future increased food demand due to population growth it will be necessary not only to address yield losses, but also reverse them. Several broad strategies (and combinations) for ameliorating landscape yield loss are possible. These include adding new land, removing degraded land, technological innovation and regenerating degraded land with alternative agricultural practices. Although these strategies may be possible in principle, in practice they may not.

As discussed previously, while short-term addition of new land is possible and is occurring in Australia as well as many developing countries, this strategy is considerably constrained by a number of factors. Aside from obvious, geographical constraints, it is well known that, globally, we are exceeding our planetary boundaries for land system change, biochemical flows (use of phosphorus and nitrogen), biosphere integrity (formerly biodiversity loss) and climate change (Steffen et al., 


\section{Distribution of landscape yield loss}

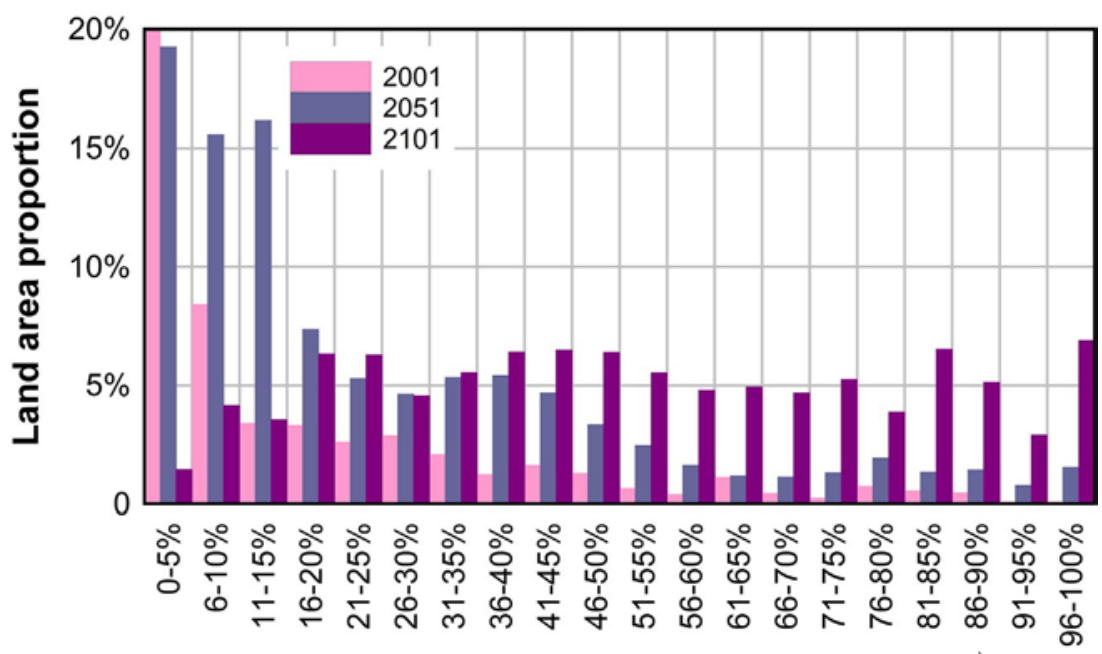

Yield loss bracket

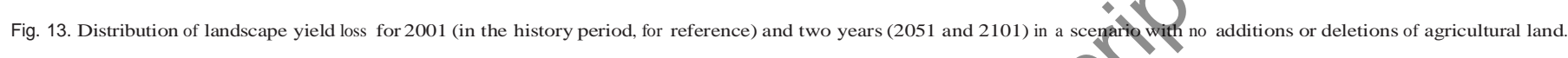

2015). All of these are at least partially caused by global agricultural production and would be exacerbated by bringing new land under cultivation. Only adding new land would also not address the affect of degraded land on climatic systems and climate change, one of the two most important planetary boundaries to avoid crossing according to Steffen et al. (2015).

Alternatively, degraded land could be removed from production. However, future contractions in the area cultivated could also mask the impacts of yield losses, as the more degraded paddocks are those that are likely to be retired first. The retired land could be employed for other purposes such as reafforestation for greenhouse gas mitigation. This approach constrains growth in crop production as total productive area reduces, and also cannot be an on-going strategy since some land must be retained for food production.

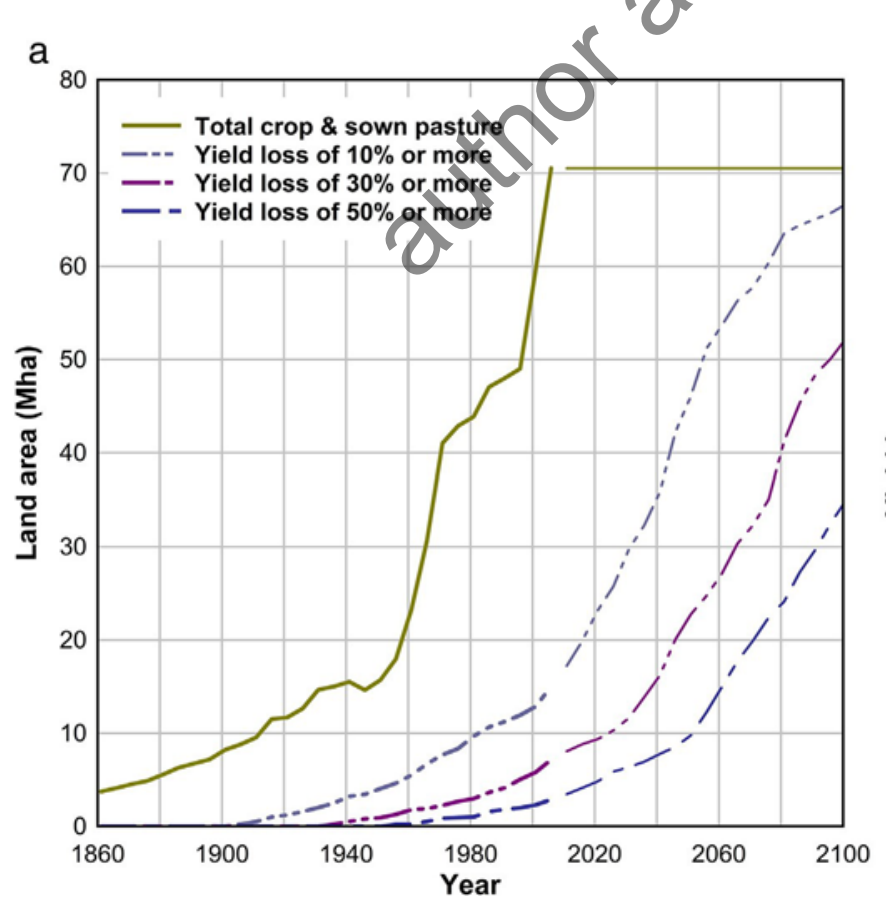

The third strategy would seek to extend the "green revolution" through technological innovation. The array of technologies available to agriculture is enormous and the potential for further improvements is considerable. In a study of 13 global degradation hotspots using scenario analysis, Fleskens et al. (2014) found that there is significant scope to combat land degradation and raise agricultural productivity at moderate cost. However, the technologies and farming systems of the future must not only deliver higher potential yields, they must also deal with declining soil fertility, increasing sodic, saline and acidic soils, rising water tables, soil structural decline, erosion, droughts, floods, water logging, pests and pathogens, the off-site effects of exported water, nutrients and salt, and any emerging new opportunities and threats (Poole, 1998). Our analysis suggests that an additional $15 \%$ yield increase is required by mid-century simply to offset land

b

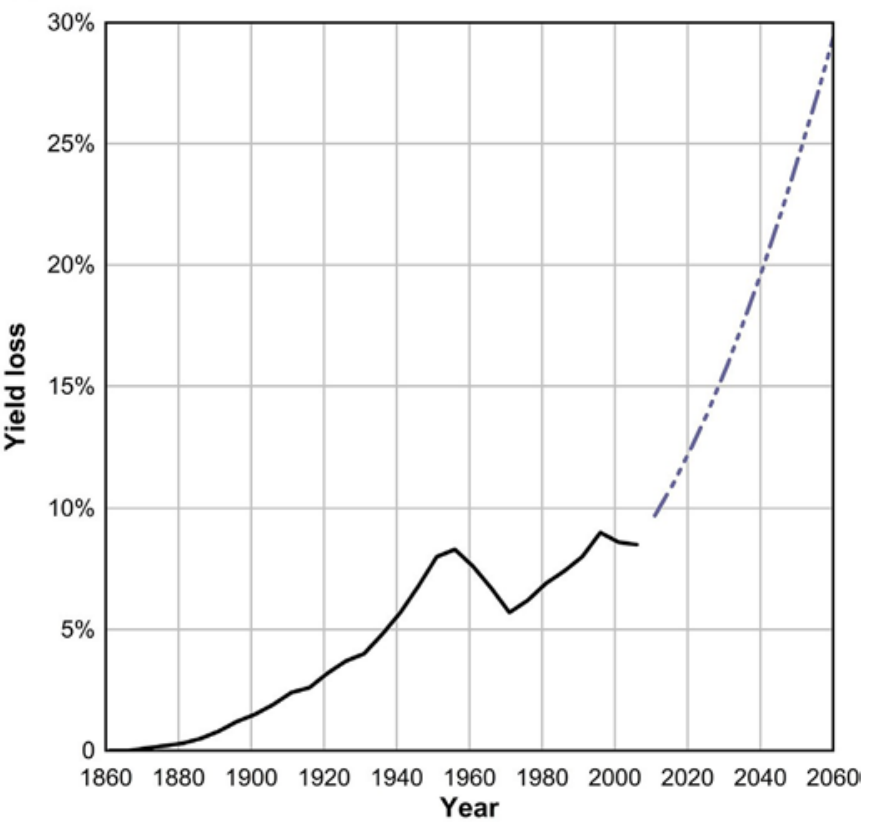

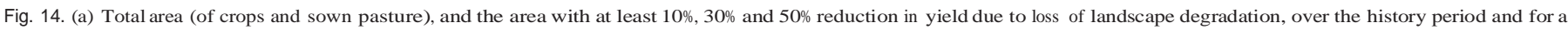
scenario (from 2011, thin lines) with no additions or deletions of agricultural land. (b) Relative yield loss (average area-weighted) for the history period and simulated scenario. 
degradation. If the focus of technological innovation simply continued the current trend of more intensive use of existing agricultural land (Tilman et al., 2011), the effects would be similar to those of adding new land, the impacts of which, in the long term, are unclear (Godfray et al., 2010).

Finally, alternative agricultural practices could be employed to reverse landscape deterioration. A range of potential options exist, which typically involve some simultaneous or sequential mix of crops, pastures and/or grazing. Such practices remain as productive food systems, but the rate and scale of change required and implications for other inputs, such as human labour, has not been fully assessed. A current food security project is underway examining these and other issues using this cropping model embedded in the Australian Stocks and Flows Framework; this is a more detailed and wider analysis following a pilot project for the state of Victoria (Turner et al., 2012).

\section{Conclusions}

Taking a long-term perspective on the historical development of agriculture (especially cropping) in Australia has provided significant insights into several key factors underpinning crop production. These insights have important implications for the required future crop production deemed necessary to feed a growing global population-implications which may apply to other countries and not just to Australia.

A simple comparison of production volume against cropping area shows that production scales strongly with area in Australia. Only in recent decades (from about 1970 onward) does production increase faster than a linear function of area-and notably this happens when substantial additions of land were made. This indicates that the large growth in Australian cropping is not so much a result of the "green revolution" as a "brown revolution" associated with land-clearing. This is not to say that technological innovations, such as genetic improvements and industrial inputs, have not and cannot contribute to yield growth, just that a reliance on these as the primary factor is misplaced.

Associated with this is the role that land degradation plays. Our calibrated land-cropping model demonstrated that yield plateaus observed in Australian cropping through 1930-1970 are explained by non-linear degradation processes driven by "ageing" of land that has been in production for decades. When land expansion is halted, yield losses due to degradation have negatively offset gains made through fertilisation, irrigation and genetic improvements. Typically, growth in yield due to the latter factors may resume when new land is added to the cumulative stock.

However, yield growth with land expansion is not always the case, as demonstrated when the model was validated against data from the recent decade. This period was one of only a few times in Australian cropping history when the total land area increased, but production did not go up. The simulated production agreed with the observed data when this land area was used as input to the model, holding other inputs constant (including a 30-year average of the climate yield factor). Climatic factors have a strong influence on production, resulting in large yearly variations typical of Australian agriculture. Evidently, longer term effects associated with climate change may become significant, and compound degradation impacts.

It would be interesting to consider if land ageing might be a contributing factor to observed plateauing of yields in recent decades for key crops and regions beyond Australia. Yield plateaus appear in developed countries, where agricultural land expansion is likely to be constrained. (Also, yields have risen for many decades, reaching about $80-90 \%$ of the potential yield limit.) In contrast, in many developing countries where agricultural land expansion may be continuing, yields are still increasing. This observation is generally consistent with our model, pointing to the need for further research on impacts of land degradation.

The importance of this research is highlighted by our findings that potential degradation impacts due to evident constraints in land expansion could lead to a doubling of yield losses within a few decades (in Australia). This may potentially counter yield improvements from technological progress, such that food production is insufficient for projected population growth.

\section{Acknowledgements}

This research was funded or supported in part by the Rural Industries Research and Development Corporation (CWE17), the Commonwealth Scientific and Industrial Research Organisation, Grains Council of Australia/Grains Research and Development Corporation, and an Australian Research Council Linkage Grant (LP120100168) (Modelling policy interventions to protect Australia's food security in the face of environmental sustainability challenges). We would like to recognise the technical guidance of whatIf? Technologies ${ }^{\circledR}$ who are the originators of the software we used.

The authors would also like to thank several reviewers for improvements to the manuscript.

\section{References}

Angus, J.F., 2001. Nitrogen supply ând demạnd in Australian agriculture. 41, 277-288. ASEC, 2002. Australia State of the Environment 2001. Australian State of the Environment Committee, Environment Australia, Canberra.

BOM, CSIRO, 2014. State of Climate 2014. Buearu of Meterology and CSIRO.

Burch, G., Graetz, D., Noble, 1., 1987. Biological and physical phenomena in land degradation. In: Chisholm, A., Dumsday, R. (Eds.), Land Degradation: Problems and Policies. Cambridge University Press, Cambridge.

Camm, J.C.R., Mcquilton, J., 1987. Rural landscapes. Australians: a Historical Atlas. Fairfax, Syme and Weldon Associates, Sydney.

Camm, J.C.R., Mcquilton, J., Plumb, T.W., Yorke, S. (Eds.), 1987. Australians, a Historical Atlas, Broadway. Fairfax, Syme \& Weldon, N.S.W.

CRCSLM, 1999. The Costs of Soil Acidity, Sodicity and Salinity for Australia: Preliminary Estimates. CRC Soil \& Land Management, Adelaide.

CSIRO, 2009. Northern Australia Land and Water Science Review 2009 Chapter Summaries. Northern Australia Land and Water Taskforce, Canberra.

De Jong, R., De Bruin, S., Schaepman, M., Dent, D., 2011. Quantitative mapping of global land degradation using earth observations. Int. J. Remote Sens. 32, 6823-6853.

Dent, D.L., Asfary, A.F., Giri, C., Govil, K., Hartemink, A., Holmgren, P., Keita-Ouane, F., Navone, S., Olsson, L., Ponce-Hernandez, R., Rockström, J., Shepherd, G., 2007. Land. In: Kassas, M. (Ed.), UNEP Global Environment Outlook 4 (GEO4): Environment for Development. Progress Press, Valletta.

Donald, C.M., Williams, D.B., 1982. The progress of Australian agriculture. Agriculture in the Australian Economy. Sydney University Press, Sydney.

Dunlop, M., Turner, G., 2003. Future Sustainability of the Australian Grains Industry; Report for the Grains Council of Australia. CSIRO Sustainable Ecosystems, Resource Futures Program, National Futures.

Dunlop, M., Foran, B., Poldy, F., 1999a. Modelling agricultural production and landscape biophysical function in Australia. Resource Futures Program Working Paper 99/15. CSIRO Wildlife and Ecology, Canberra.

Dunlop, M., Mckenzie, N., Jacquier, D., Ashton, L., Foran, B., 1999b. Australia's stocks of quality soils. Resource Futures Program Working Paper 99/06. CSIRO Wildlife and Ecology, Canberra.

Dunlop, M., Turner, G., Foran, B., Poldy, F., 2002. Decision Points for Land and Water Futures. CSIRO Sustainable Ecosystems, Resource Futures Program, National Futures, Canberra.

Fleskens, L., Nainggolan, D., Stringer, L.C., 2014. An exploration of scenarios to support sustainable land management using integrated environmental socio-economic models. Environ. Manag. 54, 1005-1021.

Glantz, M.H., Orlovsky, N.S., 1983. Desertification: a review of the concept. Desertification Control Bulletin.

Godfray, H.C.J., Beddington, J.R., Crute, I.R., Haddad, L., Lawrence, D., Muir, J.F., Pretty, J., Robinson, S., Thomas, S.M., Toulmin, C., 2010. Food security: the challenge of feeding 9 billion people. Science 327, 812-818.

Grassini, P., Eskridge, K.M., Cassman, K.G., 2013. Distinguishing between yield advances and yield plateaus in historical crop production trends. Nat. Commun. 4, 1-11.

Gregory, P.J., George, T.S., 2011. Feeding nine billion: the challenge to sustainable crop production. J. Exp. Bot. 62, 5233-5239.

Hamblin, A., Kyneur, G., 1993. Trends in Wheat Yields and Soil Fertility in Australia. Bureau of Resource Sciences, Canberra.

Hatton, T., 2000. Soils and Catchment Ecohydrology. In: Sarre, A. (Ed.), Fixing the Foundations: The role of soil science in solving Australia's crisis in land and water management. Australian Academy of Science, Canberra.

Henzell, T., 2007. Australian Agriculture: its History and Challenges. CSIRO Publishing, Collingwood, Vic.

NLWRA, 2001. Australian Agricultural Assessment 2001. National Land and Water Resources Audit, Canberra.

NLWRA, 2002. Australians and Natural Resource Management 2002. National Land and Water Resources Audit, Canberra. 
Okin, G.S., Murray, B., Schlesinger, W.H., 2001. Degradation of sandy arid shrubland environments: observations, process modelling and management implications. J. Arid Environ. $47,123-144$.

PMSEIC, 1998. Dryland salinity and its impacts on rural industries and the landscape. Prime Minister's Science, Engineering; Innovation Council Occasional Paper No. 1. Department of Industry, Science and Resources, Canberra.

Pollard, J., 2000. A hundred years of agriculture. Year Book Australia 2000. ABS, Canberra.

Poole, M., 1998. New cropping systems and their underlying technologies and challenges. Technology - Australia's future. New Technology for Traditional Industries; Engineering Symposium November. Australian Academy of Technological Sciences.

Pratley, J., Robertson, A. (Eds.), 1998. Agriculture and the Environmental Imperative. CSIRO Publishing, Collingwood.

Prospero, J.M., Lamb, P.J., 2003. African droughts and dust transport to the Caribbean: climate change implications. Science 302, 1024-1027.

Schlesinger, W.H., Reynolds, J.F., Cunningham, G.L., Huenneke, L.F., Jarrell, W.M., Virginia, R.A., Whitford, W.G., 1990. Biological feedbacks in global desertification. Science 247 1043-1048.

Shaw, A.G.L., Davidson, B., 1995. Agriculture: the first 200 years. In: Douglas, F. (Ed.), Australian Agriculture: the Complete Reference on Rural Industry. Morescope, Camberwell.

Smil, V., 2001. Enriching the Earth: Fritz Haber, Carl Bosch, and the Transformation of World Food Production. The MIT Press, Cambridge.

Steffen, W., Richardson, K., Rockstrom, J., Cornell, S.E., Fetzer, I., Bennett, E.M., Biggs, R., Carpenter, S.R., De Vries, W., De Wit, C.A., Folke, C., Gerten, D., Heinke, J., Mace, G.M., Persson, L.M., Ramanathan, V., Reyers, B., Sorlin, S.,
2015. Planetary boundaries: Guiding human development on a changing planet. Science $347,736+$

Stephens, D.J., 2002. National and regional assessments of crop yield trends and relative productivity. Report for Theme 5.1 of the National Land and Water Resources Audit. Department of Agriculture, Western Australia.

Tilman, D., Balzer, C., Hill, J., Befort, B.L., 2011. Global food demand and the sustainable intensification of agriculture. Proc. Natl. Acad. Sci. U. S. A. 108, 20260-20264.

Tribe, D.E Peel, J.L. 1988. Innovation, Science and the Farmer. Technology in Australia, 1788-1988: a Condensed History of Australian Technological Innovation and Adaptation During the First Two Hundred Years. Australian Academy of Technological Science and Engineering, Melbourne.

Turner, G.M., Hoffman, R., Mcinnis, B.C., Poldy, F., Foran, B., 2011. A tool for strategic biophysical assessment of a national economy - the Australian stocks and flows framework. Environ. Model Softw. 26, 1134-1149.

Turner, G.M., Larsen, K.A., Ryan, C., Lawrence, M., 2012. Australian food security dilemmas-comparing nutritious production scenarios and their environmental, resource and economic tensions. In: Farmar-Bowers, Q., Higgins, V., Millar, J. (Eds.), Food Security in Australia. Springer.

Van Ittersum, M.K., Cassman, K.G., 2013. Yield gap analysis-rationale, methods and applications-introduction to the special issue. Field Crop Res. 143, 1-3.

Van Ittersum, M.K., Cassman, K.G., Grassini, P., Wolf, J., Tittonell, P., Hochman, Z., 2013 Yield gap analysis with local to global relevance-a review. Field Crop Res. 143, 4-17.

Walcott, J., 2001. Land use change, productivity and diversification. Final Report of Theme 5.1 to the National Land and Water Resources Audit. Bureau of Rural Sciences, Canberra.

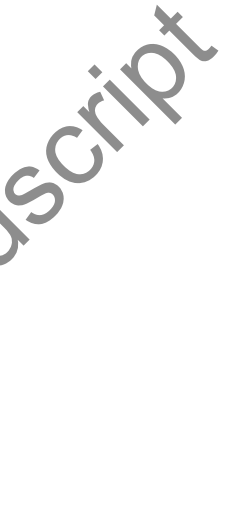




\section{University Library}

\section{- M M N E R VA A gateway to Melbourne's research publications}

Minerva Access is the Institutional Repository of The University of Melbourne

Author/s:

Turner, GM;Dunlop, M;Candy, S

Title:

The impacts of expansion and degradation on Australian cropping yields-An integrated historical perspective

Date:

2016-03-01

Citation:

Turner, G. M., Dunlop, M. \& Candy, S. (2016). The impacts of expansion and degradation on Australian cropping yields-An integrated historical perspective. AGRICULTURAL SYSTEMS, 143, pp.22-37. https://doi.org/10.1016/j.agsy.2015.11.006.

Persistent Link:

http://hdl.handle.net/11343/121778 